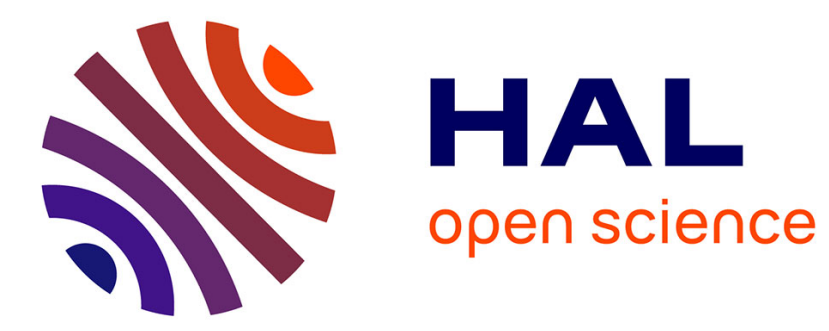

\title{
Shipment Frequency of Exporters and Demand Uncertainty
}

Gabor Békés, Lionel Fontagné, Balazs Murakozy, Vincent Vicard

\section{To cite this version:}

Gabor Békés, Lionel Fontagné, Balazs Murakozy, Vincent Vicard. Shipment Frequency of Exporters and Demand Uncertainty. 2014. hal-01299838

\section{HAL Id: hal-01299838 \\ https://hal.science/hal-01299838}

Preprint submitted on 8 Apr 2016

HAL is a multi-disciplinary open access archive for the deposit and dissemination of scientific research documents, whether they are published or not. The documents may come from teaching and research institutions in France or abroad, or from public or private research centers.
L'archive ouverte pluridisciplinaire HAL, est destinée au dépôt et à la diffusion de documents scientifiques de niveau recherche, publiés ou non, émanant des établissements d'enseignement et de recherche français ou étrangers, des laboratoires publics ou privés. 


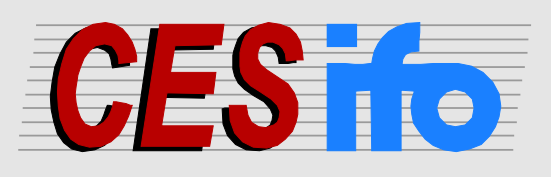

\title{
Working Papers \\ www.cesifo.org/wp
}

\section{Shipment Frequency of Exporters and Demand Uncertainty}

\author{
Gabor Békés \\ Lionel Fontagné \\ Balazs Murakozy \\ Vincent Vicard
}

CESIFO WORKING PAPER NO. 4734

CATEgory 8: TRAde Policy

APRIL 2014
An electronic version of the paper may be downloaded
- from the SSRN website:
- from the RePEc website:
WwW.SSRN.com
www.RePEc.org
- from the CESifo website:
www.CESifo-group.org/wp

\section{CESifo}




\title{
Shipment Frequency of Exporters and Demand Uncertainty
}

\begin{abstract}
Firms adjust to differences in market size and demand uncertainty by changing the frequency and size of their export shipments. In our inventory model, transportation costs and optimal shipment frequency are determined on the basis of demand as well as inventory and per shipments costs. Using a cross section of monthly firm-product-destination level French export data we confirm that firms adjust on both margins for market size. In a stochastic setting, firms adjust to increased uncertainty by reducing their sales and, for a given export volume, by reducing their number of shipments and increasing their shipment size.
\end{abstract}

JEL-Code: D400, F120, R400.

Keywords: gravity, transport costs, frequency of trade, inventory model, firms.

Gabor Békés

Institute of Economics, CERS-HAS

Budapest / Hungary

bekes@econ.core.hu

Balazs Murakozy

Institute of Economics, CERS-HAS

Budapest / Hungary

murakozy@econ.core.hu
Lionel Fontagné

Paris School of Economics

University of Paris 1, Panthéon-Sorbonne

Maison des Sciences Economiques

106-112 Bd de l'Hôpital

France - 75647 Paris Cedex 13

lionel.fontagne@univ-paris1.fr

Vincent Vicard

Bank of France

Paris / France

vincent.vicard@banque-france.fr 


\section{Shipment frequency of exporters and demand uncertainty*}

\section{Introduction}

Consider an exporting firm's management problem: how many Barbie dolls should I ship from my Chinese assembly line to the UK for next Christmas? This question illustrates uncertainty on demand (children might prefer electronic devices this year) aggravated by distance (Guangzhou to Southampton is up to a 30 days sailing route) and inventory costs. Posting new orders in case of underestimation of demand will be very costly (air delivery), while ordering more than demanded means storing unsold dolls. Hence, uncertainty faced by the firm is positively affected by the uncertainty of demand and the time to ship (aggravated here by perishability given season specific demand).

This is indeed an extreme case of a more fundamental optimization problem faced by firms making decisions on the size of likely sales and on the modes and details of how to best serve their clients. There is no just-in-time service when products have to be traded internationally. International exchange - where clients are located at large distance from the supplier - is thus a good laboratory to study how firms adjust their sales technology i) to variations in demand across markets and ii) in presence of uncertainty, using frequency of delivery as a margin of adjustment. From a trade perspective, shipment frequency is another margin of exports worth studying: the question is neither whether

${ }^{*}$ Corresponding author: Békés: bekes@econ.core.hu, CERS-HAS, Budaörsi út 45, Budapest, Hungary. We thank Zsuzsa Holler for excellent research assistance. For comments and suggestions, we are grateful to Carlo Altomonte, Colin Cameron, Jonathan Eaton, Mikos Koren, Thierry Mayer, Adam Szeidl and seminar participants at UC Davis, CEU (Budapest), LMU (Munich), ETH (Zurich), PSE \& Sciences Po (Paris), Banque de France (Paris), EEA 2012, ETSG 2013. The authors gratefully acknowledge financial assistance from the European Firms in a Global Economy: Internal policies for external competitiveness (EFIGE), a collaborative project funded by the European Commission's Seventh Framework Programme (contract number 225551), MTA Momentum Programme and MTA Bolyai Grant. Békés thanks the hospitality of CEPII. Fontagné thanks the hospitality of CESifo. This paper represents the views of the authors and should not be interpreted as reflecting those of Banque de France. 
you export (extensive firm margin), nor how much you export (intensive margin), but how often you export, conditional on your foreign sales. ${ }^{1}$

The transaction margin has already been observed in the trade literature, but received limited attention. ${ }^{2}$ The well-known Baumol-Tobin framework provides a good description for determining the optimal combination of the number of shipments and value per shipment for different export markets in a deterministic setting, given the transport technology. Kropf \& Saure (2012) derive a Melitz-type model encapsulating fixed costs of shipping and show that higher fixed costs reduce the frequency of shipments and increase value per shipment. ${ }^{3}$ Another related paper is Hornok \& Koren (2011), in which consumers have a preference for frequent shipments in relation to a higher utility of timely consumption. In this setup per-shipment costs reduce shipment frequency, increase shipment size and the product price. ${ }^{4}$

In this paper we extend this deterministic case to the additional question: how uncertainty of demand affects the number of shipments and their size. This issue is complex because uncertainty increases logistics costs and makes holding relatively larger inventories optimal in order to reduce backorder costs. Larger logistics costs lead to smaller trade volume. Reduced export volume together with larger optimal inventories both affect trade frequency negatively. For shipment size, however, the effect of increased uncertainty is less clear cut: the negative effect of reduced exports may be subdued by the increase in the relative size of shipments required to maintain a relatively larger inventory level. We address these issues based on the review of Zipkin (2000) - an established text from the area of logistics and inventory optimization. ${ }^{5}$

Inventory models - standard in the theory of logistics management - have been shown to be useful frameworks when explaining the impact of large demand shocks in presence of transaction and inventory costs (Alessandria et al. 2011). The models in

\footnotetext{
${ }^{1}$ Firms can also adjust by shipping different set of or products and/or to a different set of destinations. Iacovone \& Javorcik (2010) examine how uncertainty affects trade patterns considering product level dynamics within firms for Mexico. The margin of adjustment here falls on products and uncertainty leads to product churning and limited value for new flows. In these cases, experience discussed by Araujo \& Ornelas (2007) and Albornoz et al. (2012) help explain exporters' behavior. We will here focus on product-destination decisions: we assume that firms have already chosen their portfolio of exported product to each destination.

${ }^{2}$ When analyzing Colombian transaction-level data, Eaton et al. (2008) show that the distribution of number of transaction is highly skewed, and that the transaction contributes to total trade significantly. Ariu (2011) also decomposes trade using the number of transactions using monthly trade data for Belgium and finds the transaction margin to be important at both the firm-level and country level decompositions.

${ }^{3}$ Using Swiss data they estimate per shipment fixed costs at 6,500 USD in 2007.

${ }^{4}$ Also, on explicit modeling of trade technology, see Behrens \& Picard (2011) or Kleinert \& Spies (2011).

${ }^{5}$ We deviate from the literature (Hornok \& Koren 2011, Hummels \& Schaur 2013) by focusing on the supply side and firm level maximization in the presence of simple demand function. More precisely, we concentrate on logistics decisions and hence, the cost function of transportation, rather than organizational decisions.
} 
Alessandria et al. (2010) and Alessandria et al. (2011) were designed to explain time series evidence after large trade shocks. They consider a dynamic version of the decision to be made by the importer as to importing or not. Instead, our simple and tractable approach will reflect the inventory decisions of a firm exporting to many markets, and predict differences across markets and products. ${ }^{6}$

In order to study these decisions made by exporters, we use the highly disaggregated nature of monthly export data for individual exporters and consider a new margin of trade: the frequency of shipments. We will define this frequency as the number of months within a year in which an international shipment is recorded for a given firmproduct-destination. We use data from the French Customs at individual exporter level, providing monthly firm export data by destination and product category.

We firstly adopt a deterministic approach to the optimal number of shipments. A simple model allows predicting how the margins of trade (here the number of shipments and the value per shipment) adjust to different levels of foreign demand. We bring our predictions to the data by running firm-product-destination level regressions in a simple gravity framework. To control for firm heterogeneity is crucial to avoid selection biases. We confirm that the frequency of shipments is used by firms to smooth the impact of business conditions on their different markets. As predicted by the theory, the adjustment to market size is roughly channeled half through the number of shipment and half through their size.

We then address our focal question concerning the impact of uncertainty on sales, number and size of shipments. We rationalize our analysis within a stochastic inventory framework focusing on uncertainty on demand, where firms pay per shipment cost to reach their foreign clients, and pay a storage cost to store goods and serve clients as they appear. The model predicts that: (i) higher uncertainty reduces export value, the number of shipments and has an ambiguous impact on the average value of shipments; (ii) holding export value fixed, higher uncertainty reduces the number of shipments and increases the average value per shipment; (iii) the effect of uncertainty is magnified by shipment time: uncertainty only matters if transport is timely. These predictions are confirmed on our cross-section of detailed firm level export data.

Several additional issues regarding firms sales and logistic decisions are excluded from scope of this paper. When time matters, firms can optimize transport by choosing between modes of air and maritime cargo (Harrigan 2010, Hummels \& Schaur 2013). ${ }^{7}$

\footnotetext{
${ }^{6}$ Inspired by the Great Recession, Novy \& Taylor (2013) also investigates the role of macro uncertainty on trade volumes. They relate a real option model of stochastic inventory management to the trade reaction model of Bloom (2009) emphasizing the role of imported intermediate inputs. Using monthly US import and industrial production data, they suggest a link between uncertainty and macro-economic cyclicality.

${ }^{7}$ Indeed, as Hummels \& Schaur (2010) demonstrated, uncertainty of demand will affect transport behavior, in the presence of higher demand uncertainty, a greater share of shipments will be taking place via air transport. We will address this issue by restricting our estimations, in a robustness, to maritime transport.
} 
Evans \& Harrigan (2005) argue that an additional adjustment path is location choice: products that need to be served at a timely fashion will be produced closer to destination markets, thus affecting specialization patterns. ${ }^{8}$ We consider here that location choices are given, and address firms' strategies conditional on these choices. ${ }^{9}$

The remaining of the paper is structured as follows. Section 2 presents the data and provides descriptive statistics on shipment frequency for our sample. Section 3 discusses the optimal shipment policy in a deterministic setting and provides evidence that adjustment of shipment frequency to foreign market size falls half-and-half on size and frequency of shipments. Section 4 addresses the impact of uncertainty on these export margins, and describes our measurement of uncertainty. A simple model of inventory management offering testable predictions is confronted to the data. The last section concludes.

\section{Data and stylized facts}

We use detailed data from the French Customs for 2007. In the dataset the unit of observation is monthly export value by a firm $i$ of product $j$ to a destination $k$; products are treated at the 6 -digit $\mathrm{HS}$ level ${ }^{10}$. As we are interested in firm optimization, having firm identifier as well as product-destination information is crucial. Furthermore the fact that we can link exports onto different markets and products of the same firms will allow assessing the marginal association with demand, partialling out unobserved firm characteristics. Hence, we can study how the very same firm adjusts to different market conditions.

Figure 1 provides a first look at the distribution of trade frequency for incumbent exporters. The frequency of shipment is approximated by the number of months within a year in which an international shipment is recorded for a given firm-productdestination. ${ }^{11}$ The most important message of the figure is that there is a large number of firms shipping their products only a few months in a year, providing us a large sample and sufficient variation to estimate the determinants of frequency.

We observe a fair number of single shipments: less than $30 \%$ of firms ship only once a year to EU markets (left panel of Figure 1) but $45 \%$ do so to extra-EU markets (resp. right panel). More than $10 \%$ of exporters ship their products every month to their EU markets, as opposed to a smaller fraction towards extra-EU markets. Note that when

\footnotetext{
${ }^{8}$ Uncertainty is indeed impacting many other dimensions of individual firms decisions, like investment in presence of irreversibility (Bloom \& Van Reenen 2007), in line with the traditional real option argument (Dixit \& Pindyck 1994). We focus here on trade models.

${ }^{9}$ We use export data for one exporting country, and consider as a robustness maritime routes only.

${ }^{10}$ We excluded Ships and Aircraft because these items are not exported through usual transport technology but through self-propulsion.

${ }^{11}$ This does not exclude indeed more than one shipment in a month for a given firm, but we will loosely associate month in which a shipment is recorded to "shipment".
} 
all exporters are included instead of incumbents only, there is a much larger proportion of firms exporting only within a single month of 2007, as shown in Appendix, Figure 7.

Figure 1: Frequency of shipments, number of months, 2007, all and extra-EU, incumbents exporters
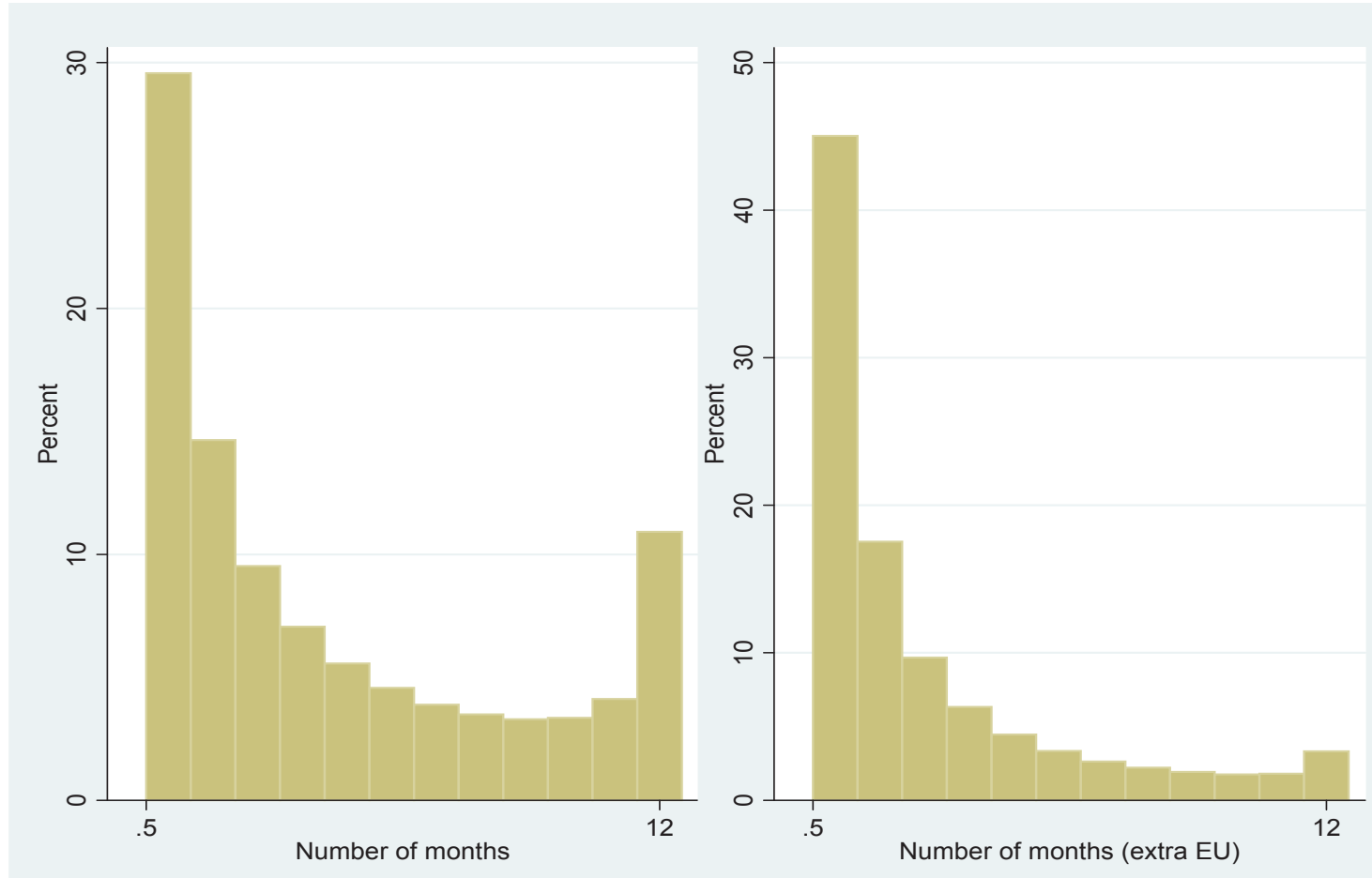

Notes: firm-destination-product (HS6) level. Source: French Customs, authors' calculation.

Table 1 provides statistics on the heterogeneity of export frequency. Interestingly, the upper quartile is corresponding to five shipments only: choosing when to export is really a choice to be made by firms. The corresponding strategy has many dimensions worth looking at.

Different destinations will be served differently: in EU destinations, the frequency is higher: the median is 3 shipments compared to one for extra-EU trade relationships. This higher frequency can be driven by proximity (authorizing less costly shipments), by market size (large markets can be served more frequently), by type of products exported. ${ }^{12}$ Considering market size, we observe that destinations with above the median GDP receive more frequent shipments than destinations below the median.

The largest companies ship their products more often: the 75 th percentile of the frequency distribution for large firms is 7 compared to 3 for smaller firms. This observation underlines the importance of controlling for firm characteristics.

\footnotetext{
${ }^{12}$ Composition of exporters would impact the results the other way round (smaller exporters ship less and less frequently).
} 
Table 1: Descriptive statistics of the number of shipments (2007)

\begin{tabular}{rcccc}
\hline & Mean & p25 & Median & p75 \\
\hline Total & 3.7 & 1 & 2 & 5 \\
Within EU27 & 4.6 & 1 & 3 & 8 \\
Extra EU27 & 2.3 & 1 & 1 & 2 \\
Large countries (GDP) & 4.2 & 1 & 2 & 7 \\
Small countries (GDP) & 2.8 & 1 & 1 & 3 \\
Large firms & 4.3 & 1 & 2 & 7 \\
Small Firms & 2.8 & 1 & 1 & 3 \\
\hline \hline
\end{tabular}

\section{Gravity and frequency as a margin}

Before turning to the discussion of uncertainty, let us put some theory on these stylized facts. A simple model of deterministic inventory management can help understanding how demand (market size) shapes exporters' decisions and serve as reference when studying uncertainty. We embody a simple model of steady state behavior based on Zipkin (2000) into a framework with CES demand on foreign markets and confront its predictions with data. The starting point of this framework is the idea of inventory management, where firms optimize inventory decisions under different circumstances. The simplest such models investigate the optimal policy under a constant demand rate, and hence, are deterministic in nature.

\subsection{Optimal frequency of shipments in a deterministic envi- ronment}

One can easily describe how trade frequency (the number of shipments of a product, per year, by a firm, to a given country) changes when explicitly accounting for logistical/operation management decisions of firms. The reasoning is similar to that of the well known transaction model of demand for cash by Baumol (1952) and Tobin (1956). In this setup firms consider external demand at each of their (product-destination) markets and optimize their shipment process based on available cost information. We assume that the firm operates a warehouse in the foreign market from which it directly sells to final consumers.

In the deterministic framework, the firm faces a demand of $\lambda$ in each time period, has to pay a per-shipment cost of $k$ each time when placing an order, the variable cost of transportation is $\tau$, and holding one unit of inventory costs $h$ per unit of time. Inventory cost shall include all costs related to storage such as rent, running cost of facilities and personnel. Furthermore, it includes the cost of capital that covers the value of stored goods, which may be affected by the financial position of the firm. In the simplest case, the firm has to hold enough inventory to satisfy the demand of all customers from its holdings, hence quantity sold is exogenously determined. 
The main decision variable is the average shipment size, which, given demand is set, also determines the number of shipments per period. The tradeoff the firm faces is between more shipments implying higher per-shipment costs and more inventory holding implying higher inventory costs. Under such circumstances, the firm minimizes its total logistic cost:

$$
C(q)=\tau \lambda+k \lambda / q+h q / 2
$$

where $q$ is the average shipment size. Note that it is assumed that goods will be depleted linearly and hence, average value of goods kept abroad is half the shipment quantity. The optimal shipment size is:

$$
q^{*}=\sqrt{\frac{2 k}{h} \lambda}
$$

while the optimal number of shipments is:

$$
f^{*}=\sqrt{\frac{h}{2 k} \lambda}
$$

Hence both the number of shipments and the quantity/shipment increases in proportion to the square root of demand intensity, $\lambda$. It is optimal to adjust to larger market size on two margins: logistics costs are minimized when the firm increases both the number of shipments and shipment size in proportion to the square root of demand, as both margins has a similarly increasing marginal cost schedule.

Now we can express the optimal total logistics cost (per period) of the firm:

$$
C^{*}=\tau \lambda+\sqrt{2 h k \lambda}
$$

which takes the general form of $B \lambda+C \sqrt{\lambda}$. As we will see, this general form remains valid in more realistic inventory models as well. Note that this formula suggests that - in contrast to iceberg trade costs - there are economies of scale in logistics thanks to the presence of per-shipment costs.

An important extension of the model above, which is essential when studying the effect of uncertainty, enables firms to serve some customers with delay. ${ }^{13}$ Such backorders are costly to the firm either because consumer satisfaction is lower or because emergency shipping is very costly. We assume that the firm faces a penalty cost of $b$ per backordered unit. ${ }^{14}$ It can be easily shown that the main results of the previous model are preserved in this case. While including backorder penalty will be essential in the stochastic model, it fits nicely into the deterministic setting as well. Even when sales

\footnotetext{
${ }^{13}$ In the inventory literature this is called a planned backorder.

${ }^{14} b$ can also be interpreted as a very simple reduced form representation for models which describe in more details how firms adjust prices and quantities when the stock runs out.
} 
are know in advance, it can be optimal to let inventory fall below zero (thus, paying penalty $b$ ) to save on financing the whole stock for an additional moment.

First, both optimal shipment size and frequency are proportional to $\sqrt{\lambda}$ :

$$
q^{*}=\sqrt{\frac{2 k \lambda}{h \omega}} ; f^{*}=\sqrt{\frac{h \omega}{2 k} \lambda}
$$

where $\omega=\frac{b}{b+h}$ is the relative size of the backorder penalty. The total optimal logistics cost also takes the form of $B \lambda+C \sqrt{\lambda}$ :

$$
C^{*}=\tau \lambda+\sqrt{2 h k \omega \lambda}
$$

Note that in this model investigate a direct exporter, and assume that the firm pays all logistic costs and sells to foreign clients directly from its warehouse in the foreign country. We do not consider this a very strong restriction, however. While many firms work with several buyers and customers, a great deal of firms are supplying overseas firms under an agreement, or even making specific products ordered by foreign partners. Yet, this does not change the overall validity of this setup, because the two parties face the same structure of costs and sources of uncertainty. ${ }^{15}$

\subsection{Optimal frequency with CES demand}

Until now, we have assumed that quantity is exogeneous. It is, however, an endogenous decision affected by transportation technology and logistics costs. In this subsection we will embed the firm level decisions into a framework with CES demand in the foreign market.

Let us consider one particular market and assume that the demand for firm $i$ is given by the CES demand function in that export market:

$$
\lambda_{i}=\frac{I}{P^{1-\sigma}} p_{i}^{-\sigma} .
$$

Where $I$ denotes income, and $P$ the price level in the export market. Combining the CES demand function with the cost function from the previous subsection yields the following profit function:

\footnotetext{
${ }^{15}$ For instance, consider a case when a French company exports a consumption good to the US on orders of a large retail chain. In this case, it may be the retailer who pays the costs and takes the risks but it will make decisions based on the same information set and facing the same demand and cost conditions. As a result, the effect of demand and cost variables on frequency of shipments shall be qualitatively similar to the case where exporters conditions minding final consumers. Of course, transaction prices may be different in the two settings; logistic costs will then be excluded from sales price. Also, the impact of firm characteristics such as financial strength (capacity for lending) may depend upon which partner we consider but this is not central to our case.
} 


$$
\Pi_{i}=\frac{I^{\frac{1}{\sigma}}}{P^{\frac{1-\sigma}{\sigma}}} \lambda_{i}^{\frac{\sigma-1}{\sigma}}-(c+\tau) \lambda_{i}-\sqrt{2 h k \omega} \lambda_{i}^{\frac{1}{2}} .
$$

This function is maximized when:

$$
\frac{\sigma-1}{\sigma} \frac{I^{\frac{1}{\sigma}}}{P^{\frac{1-\sigma}{\sigma}}} \lambda_{i}^{-\frac{1}{\sigma}}-(c+\tau)-\frac{1}{2} \sqrt{2 h k \omega} \lambda_{i}^{-\frac{1}{2}}=0 .
$$

This equation does not have a closed-form solution, but one can calculate how quantity is affected by the exogenous variables by implicit function differentiation. In the following paragraphs, we are interested in the effects of market size, $I$, and trade cost, $\tau$.

First, consider market size, $I$. Figure 2 shows the optimal decision on two markets with different $I$. It shows that taking into account inventory costs leads to lower quantity on both markets than a firm which only pays iceberg transportation costs. Also, the firm facing inventory costs increases its sales to a larger degree as market size increases, thanks to increasing returns to logistics. It is also shown by implicitly differentiating the first order condition:

$$
\frac{d \lambda_{i}}{d I}=\frac{\lambda_{i}}{I-\frac{1}{4} \frac{\sigma^{2}}{\sigma-1} \sqrt{2 h k \omega}\left(\frac{I}{P}\right)^{\frac{\sigma-1}{\sigma}} \lambda_{i}^{\frac{2-\sigma}{2 \sigma}}}
$$

To gain some intuition for this equation, assume first that holding inventories is costless, hence $h=0$. In such a case, $\frac{d \lambda}{d I}=\frac{\lambda}{I}$ : as in the iceberg Dixit-Stiglitz model, sold quantity is increasing linearly as income increases.

When inventory costs are non-zero, however, quantity increases more than proportionally with demand because of the decreasing marginal cost driven by the logistics technology (whenever $\sigma>1$ ), as illustrated by Figure 3. The degree of nonlinearity of the marginal cost function is determined by the relative size of inventory costs: the larger $\sqrt{2 h k \omega}$ is, the more convex the relationship between market size and quantity is. Besides the shape of the marginal cost function, the relationship between income and quantity is also affected by the shape of the demand function: the larger $\sigma$ is, the less linear the relationship between the two variables is.

Consider now the effect of $\tau$ on $\lambda$. With implicit differentiation:

$$
\frac{d \lambda_{i}}{d \tau}=-\frac{\lambda_{i}^{\frac{1+\sigma}{\sigma}}}{\frac{\sigma-1}{\sigma^{2}} \frac{I^{\frac{1}{\sigma}}}{P^{\frac{1-\sigma}{\sigma}}}-\frac{1}{4} \sqrt{2 h k \omega} \lambda_{i}^{\frac{2-\sigma}{2 \sigma}}}
$$

Again, when inventories are costless $(h=0)$, we get back the usual result for the CES case with iceberg trade costs. When inventories are costly, however, the smaller effective demand on more distant markets drives up the marginal costs because firms 
Figure 2: Optimal decisions with different market size

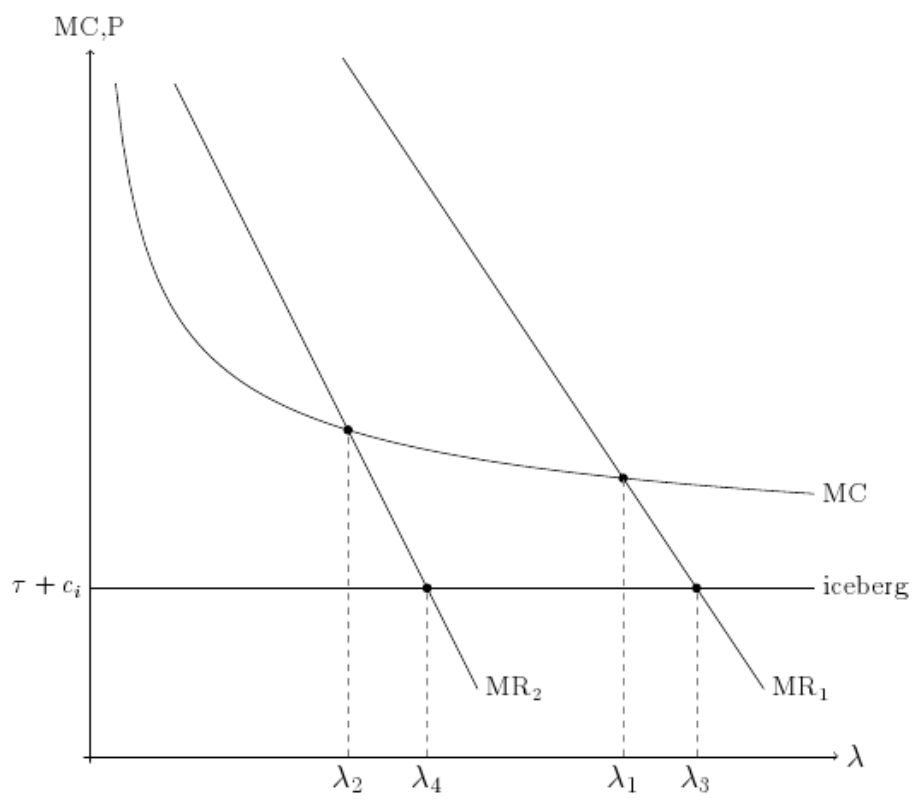

cannot benefit from increasing returns to scale in logistics technology. As a consequence, the fall in export is larger in our model than in models assuming iceberg transportation costs, and this difference is increasing in $\sqrt{2 h k \omega}$.

Finally, note that the model suggests that both the frequency and shipment size margins are increasing proportionally with the squareroot of $\lambda_{i}$. As both $I$ and $\tau$ affects frequency and shipment size only indirectly via their effect on $\lambda_{i}$, this simple inventory model predicts that the elasticity of the two margins will be the same both for market size and distance, i.e.

$$
\frac{\frac{d \ln \left(f^{*}\right)}{d \ln (I)}}{\frac{d \ln \left(q^{*}\right)}{d \ln (I)}}=\frac{\frac{d \ln \left(f^{*}\right)}{d \ln (\tau)}}{\frac{d \ln \left(q^{*}\right)}{d \ln (\tau)}}=1
$$

We will see below that such a setting is a benchmark case in presence of uncertainty. But before turning to the stochastic case, we now confront this first set of predictions to the data.

\subsection{Empirical methodology}

We considered above a demand of $\lambda$ in each period, and a total logistic cost being composed of three parts: $\tau \lambda$ the variable cost, $k \lambda / q$ the fixed cost of shipping with a frequency $\lambda / q$, and $h q / 2$ the induced inventory cost. We deduced from this that, when 
Figure 3: The relationship between optimal quantity and market size

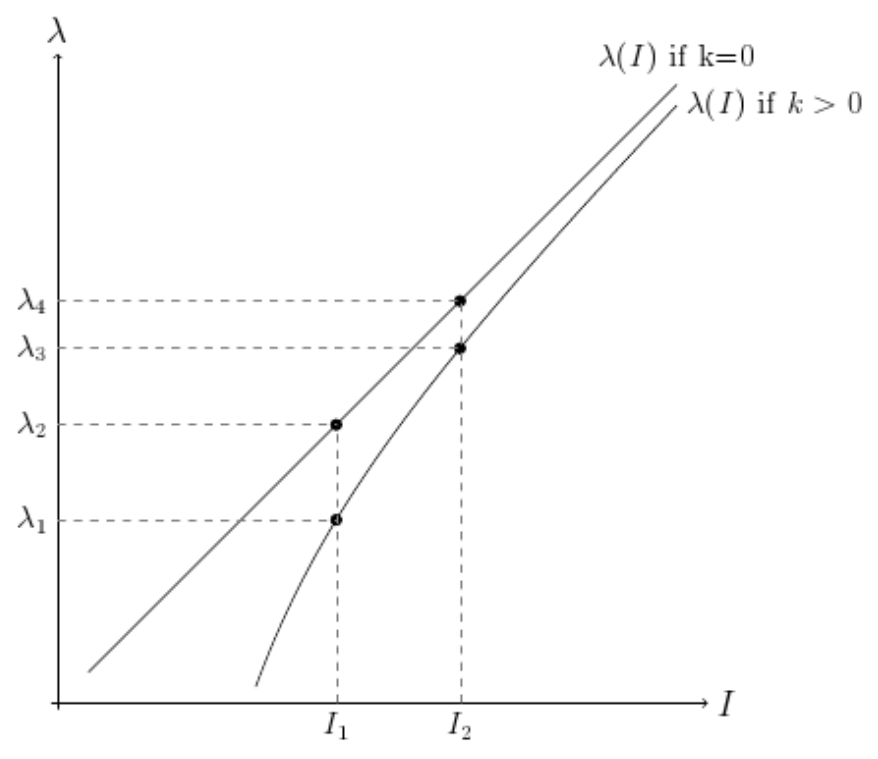

lambda is exogenous, optimal frequency $f^{\star}$ and optimal shipment size $q^{\star}$ increase in proportion to the square root of the demand $\lambda$. With endogeneous quantity we have shown that firms change their frequency and value per shipment margins to a similar extent when demand shifts or transportation cost changes.

As a result, our setup suggests that when comparing two markets for a firm, the one that is twice the size the other shall be associated with both more frequent but larger sized shipments. Predictions of the simple model presented above can now be confronted to the data asking how market conditions affect total sales, shipment frequency and average shipment size.

We use a gravity framework to decompose the different margins of exports at the firm-product level and show how the new margin of trade - frequency - is used by firms to smooth the impact of different business conditions on their different markets. We consider three dependent variables: Value $i j k$ the value exported by a firm $i$ of product $j$ to a certain destination $k$ in 2007, NbrShip $i j k$, the number of months where a shipment was recorded and $A v g V a l_{i j k}$, the average value of these shipments. We proxy demand shifters with GDP and variable transportation costs by distance. ${ }^{16}$ Composition effects will be sorted out controlling for unobservable firm-product characteristics with fixed effects $\theta_{i j}$. This leads to the following estimating equation(s):

\footnotetext{
${ }^{16}$ Annual GDP data are from the World Bank and distance come from CEPII Trade Dataset.
} 


$$
\ln Z_{i j k}=\alpha+\beta_{1 v} \ln G D P_{k}+\beta_{2 v} \ln D i s t_{k}+\theta_{i j}+\epsilon_{i j k}
$$

with $Z_{i j k}=$ Value $_{i j k}, N b r S h i p_{i j k}, A v g V a l_{i j k}$. All variables are taken in logarithm allowing us to observe that adding estimated coefficients on the average value and the number of shipments will yield the coefficient of the total value. Standard errors are clustered at the destination level.

Equations (11) will be estimated including $\theta_{i j}$ product-firm fixed effects in order to control for composition effects. Selection matters as more productive firms selfselect into different countries, because they are the ones that can pay the sunk of exports to harder markets (Mayer \& Ottaviano 2011, Arkolakis 2010). Additionally, unobserved cost characteristics may be related to both firm features such as discount rate on revenues or products such as weight. Having firm-product fixed effects imply that identification comes from differences only across destinations for the same product and firm. Note that adding firm-product fixed effects implies that single-product, singledestination (outside the EU) exporters are not considered.

There are a number of issues to consider regarding our estimation strategy.

Excluding EU countries: different thresholds apply to the collection of export data for EU and non-EU countries making a combined sample problematic to analyze. ${ }^{17}$ Also, transport within the EU is mostly swift and time and distance plays a much smaller role. We therefore restrict the sample used in econometrics to extra-EU exports, which also guarantees that we will disregard neighboring countries. ${ }^{18}$

Excluding new entrants A potentially important issue when looking at frequency in a particular year is the impact of entries. Entrants do not have a full year of presence in general (e.g. they can enter in June 2007) which is flawing any attempt of measuring export frequency or even export performance (Berthou \& Vicard 2013). In order to address this issue, we limit our analysis in the following to incumbent firms (firms that exported in any month of 2007 a given product to a given destination and were present in 2006 for this product-destination pair). ${ }^{19}$ Dropping all firms that were not present in 2006, we end up with 324,056 observations (firm-product-destination with at least one shipment in 2007) instead of 568,131.

Censoring is also an important issue to tackle. One concern is that the number of months is a noisy proxy of the number of shipments in a given year. While it is a reliable approximation for low frequency exports, it may be biased for high frequency exporters. To handle this problem, we opted for the simplest treatment and excluded the upper tail

\footnotetext{
${ }^{17}$ All extra EU export shipments over 1,000 Euros are to be declared to the French Customs whereas for exports to other EU Member states the declaration is compulsory if the yearly cumulated value of exports to the other 26 EU Member states taken together is larger than 150,000 Euros.

${ }^{18}$ With the exception of Switzerland.

${ }^{19}$ Econometric results with all firms will be provided in a robustness exercise in Appendix for the model on uncertainty suggesting that results are robust to this change. Evidence on the robustness of the deterministic model is available on request.
} 
of the distribution focusing on firm-product-destination observations for 1-9 shipments. In terms of generality, this is not a very serious problem, as this requires dropping only 7.6 percent of observations. However, it implies loosing the larger exporters and the ability to identify the role of very frequent shipments - censored at 12 months. Our robustness check will later indicate that using censored data gives conservative point estimates.

\subsection{Results in deterministic setting}

We present our main results in Table 2. In this simple gravity framework aiming at providing a decomposition of the margins at stake, we consider only market size (GDP of the destination country or total imports) and distance from France as determinants of the value of firm-products exports.

Considering the three first columns of the table, we observe that three fourth of the impact of distance fall on the number of shipments. More interestingly, roughly 40 percent of the increase in exports to larger markets channels through the number of shipments. This is an important result, though below the 50 percent predicted by the simple theoretical framework above.

The last three columns of the table focus on a drawback of having GDP as a proxy for demand - its lack of product dimension. In Columns (4)-(6) of Table 2, we therefore replace GDP and use a country's total import by (HS6) product - excluding imports from France. ${ }^{20}$ Shipment frequency and shipment size are now capturing larger shipments about equally, in line with the theoretical prediction. ${ }^{21}$

To summarize, we have confirmed empirically, using an annual cross section of monthly export data at the firm-product-destination level, that it is optimal for the firm to adjust to larger market size on two margins: logistics costs are minimized when it increases both the number of shipments and shipment size in proportion to the square root of demand. Most of the action here is about $\lambda$; accordingly the prediction of the model is that firms should adjust to a large shock on $\lambda$ by adjusting their number of transactions and the average value of their shipments in similar proportion. The 2008-09 trade collapse is providing us a useful experiment. We consider in the next subsection how French firms adjusted their shipment strategy to this exceptional event.

\footnotetext{
${ }^{20}$ Data are from the BACI database by CEPII.

${ }^{21}$ Note the advantage of using log of total imports is that it is destination-product specific (contrary to GDP) but the downside is that it is not a proxy for demand only but also includes multilateral resistance which goes in the opposite direction. The insignificant coefficient on distance in column (4) may serve as evidence.
} 
Table 2: Alternative specifications of core deterministic model

\begin{tabular}{|c|c|c|c|c|c|c|}
\hline Dep.Var. & $\begin{array}{l}\quad(1) \\
\text { Tot. Value }\end{array}$ & $\begin{array}{c}(2) \\
\text { Nbr shipment }\end{array}$ & $\begin{array}{c}(3) \\
\text { Avg. Value }\end{array}$ & $\begin{array}{l}\text { (4) } \\
\text { Tot. Value }\end{array}$ & $\begin{array}{c}(5) \\
\text { Nbr shipment }\end{array}$ & $\begin{array}{c}\text { (6) } \\
\text { Avg. Value }\end{array}$ \\
\hline GDP & $\begin{array}{r}0.178^{* * *} \\
(0.010)\end{array}$ & $\begin{array}{r}0.074^{* * *} \\
(0.004)\end{array}$ & $\begin{array}{r}0.104^{* * *} \\
(0.010)\end{array}$ & & & \\
\hline Tot. Imports & & & & $\begin{array}{r}0.178^{* * *} \\
(0.010)\end{array}$ & $\begin{array}{r}0.077^{* * *} \\
(0.004)\end{array}$ & $\begin{array}{r}0.101^{* * *} \\
(0.008)\end{array}$ \\
\hline Distance & $\begin{array}{r}-0.095^{* *} \\
(0.038)\end{array}$ & $\begin{array}{r}-0.075^{* * *} \\
(0.007)\end{array}$ & $\begin{array}{r}-0.020 \\
(0.040)\end{array}$ & $\begin{array}{r}-0.064 \\
(0.043)\end{array}$ & $\begin{array}{r}-0.063^{* * *} \\
(0.005)\end{array}$ & $\begin{array}{r}-0.002 \\
(0.042)\end{array}$ \\
\hline Firm*product FE & Yes & Yes & Yes & Yes & Yes & Yes \\
\hline R-squared & 0.047 & 0.039 & 0.029 & 0.048 & 0.044 & 0.028 \\
\hline Observations & 324,056 & 324,056 & 324,056 & 313,193 & 313,193 & 313,193 \\
\hline Number of id & 154,159 & 154,159 & 154,159 & 148,294 & 148,294 & 148,294 \\
\hline $\begin{array}{l}\text { All dependent variab } \\
\text { Robust standard erro } \\
\text { respectively. }\end{array}$ & $\begin{array}{l}\text { in logs. Extr } \\
\text { in parenthese }\end{array}$ & $\begin{array}{l}\text { UU exports and } \\
\text { clustered by des }\end{array}$ & $\begin{array}{l}\text { imbent firms o } \\
\text { ation level. }{ }^{* * *}\end{array}$ & $\begin{array}{l}\text { ly. Shipment } \\
* *, * \text { denotes }\end{array}$ & $\begin{array}{l}\text { quency truncated } \\
\text { gnificance at } 10 \%\end{array}$ & $\begin{array}{l}\text { or 1-9 months. } \\
\%, 1 \% \text { level, }\end{array}$ \\
\hline
\end{tabular}

\subsection{Export frequency during the crisis}

The financial crisis of 2008/2009 and the consecutive drop in world demand led to a global collapse of commerce; the value of exports from France fell by $14.3 \%$ in 2009 . This decline was argued to have been driven by several factors such as composition and demand effects (Eaton et al. 2011) and by the intensive margin of trade (Behrens et al. 2013). As demand is one of the major determinants of the number of shipments, we can use the 2008-09 crisis as an illustration to assess the impact of demand on export behavior and assess the contribution of the shipment frequency to the drop in the intensive margin of trade during the trade collapse. Importantly, our model does not include dynamics or uncertainty and hence, these results are only suggestive.

Figure 4 shows that the distribution of shipment frequency has shifted to the left for incumbent exporters ${ }^{22}$. Once again, as the figure suggests, that there is an issue of censoring, which justifies to focus on incumbents with less than 10 transactions in $(\mathrm{t}-1)$.

To understand firm adjustment in our framework, Table 3 considers the same group of firms we used in the cross-section, and compared two margins: shipment frequency and average value of average shipments. Importantly, we disregard firm dynamics such as exit, or differences in the nature of entrants. The table shows that these margins were both important: the number of transactions on average fell by $3.4 \%$ while the

\footnotetext{
${ }^{22}$ Note that the graph is unimodal. This stems from the fact that we only considered directions with less than 10 transactions in (t-1)
} 
average value dropped by $3.8 \% .^{23}$

These results illustrate that the frequency of shipments is used by firms to smooth the impact of business conditions on their different markets even during extreme events like the trade collapse. Comparing data for two years, we found evidence that exporters confronted with the collapse of demand in 2009 did indeed adjust on both margins.

Table 3: Frequency and average size 2009 and 2008

\begin{tabular}{rccc}
\hline Year & $\begin{array}{c}\text { Nbr } \\
\text { transaction }\end{array}$ & $\begin{array}{c}\text { Average } \\
\text { value }\end{array}$ & $\begin{array}{c}\text { Nbr } \\
\text { obs. }\end{array}$ \\
\hline 2008 & 3.10 & 36785.56 & 274479 \\
2009 & 2.99 & 35403.71 & 265621 \\
\hline Change & $-3.4 \%$ & $-3.8 \%$ & \\
\hline
\end{tabular}

Incumbent firms, transaction $<10$ in $\mathrm{t}-1$

Figure 4: Distribution of frequency of shipments 2008/2009 (incumbents, <10 shipments in t-1), incumbents exporters

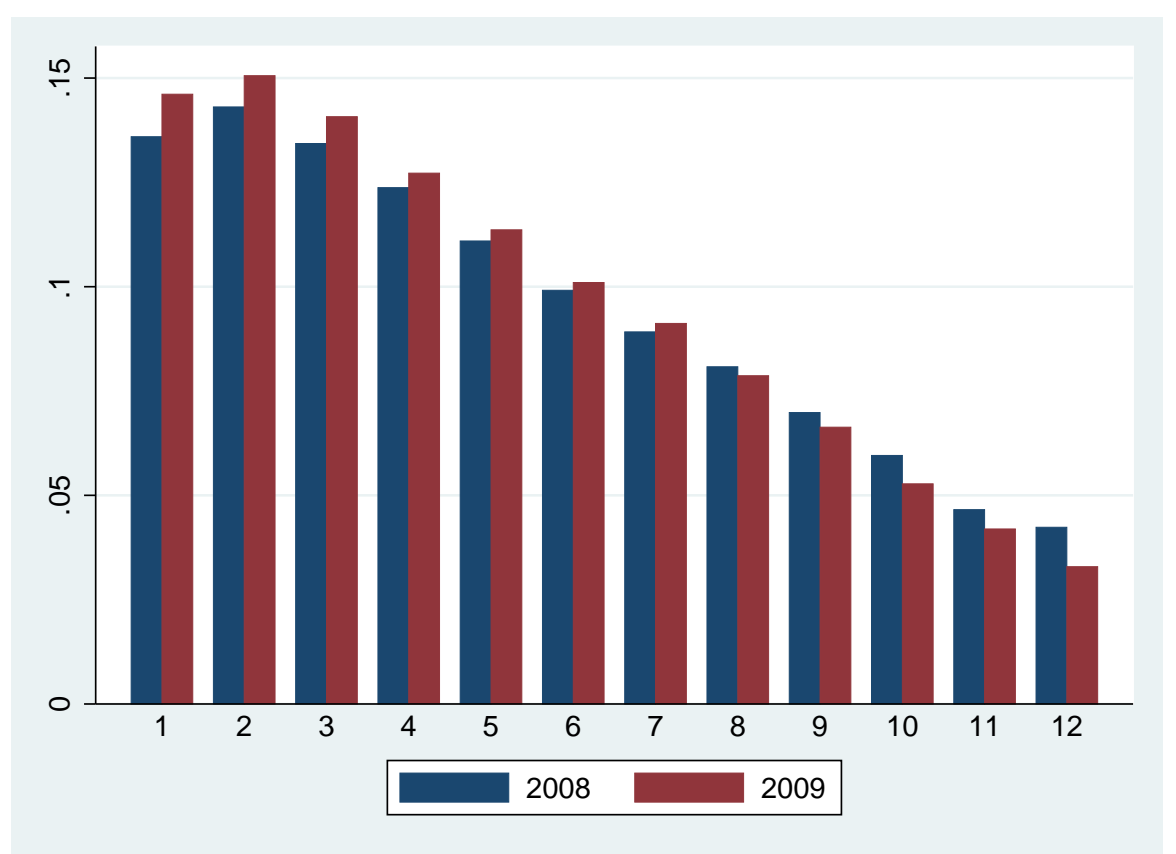

Notes: firm-destination-product (HS6) level. Source: French Customs, authors' calculation.

So far, we have considered a deterministic setting. We now shift to a more complex decision problem when the exporting firm is confronted with a stochastic demand. This requires a different modeling of her decisions regarding the optimal shipment strategy, as well as an empirically operational definition of uncertainty. The two issues are addressed in the next section.

\footnotetext{
${ }^{23}$ Note that when including firms with $11-12$ transactions, we find a greater drop in average value.
} 


\section{Uncertainty and trade margins}

Firms face uncertainty regarding their sales in all their markets - an important feature of business. In particular, we are interested in short run fluctuations of demand. In this paper, we focus on uncertainty regarding quantity - based on the anecdotal evidence that firms often have a contract with their intermediary fixing the price for a year, but not the quantity. This section studies how uncertainty affects export sales and the related margins - number and mean size of shipment - at the firm-product-destination level. Using insights from Zipkin (2000) we extend our model and derive theoretical predictions that are confronted to the data.

\subsection{Predictions of the stochastic inventory models}

While deterministic inventory models are able to capture a number of important aspects of real-world inventory problems, our second main aim is to investigate the role of demand uncertainty explicitly. For this, one has to turn to stochastic inventory models.

In such models demand follows a stochastic process. While the models are able to handle very general processes, we will concentrate on a normal approximation here. Let's start with the simplest setting whereby $\lambda$, the (expected) quantity is given. Assume accordingly that the demand $(D)$ in a period with a length of $T$ can be approximated with a normal distribution with a mean $v=E(D)=\lambda T$ and variance $\sigma^{2}=\operatorname{Var}(D)=\psi^{2} \lambda T$. Note that the expected value of this process does not depend on time, hence it is suitable to describe steady state behavior. Describing other situations, like dynamic adjustments to a large permanent shock may require other stochastic models. This is an important motivation for considering a point in time prior to the crisis and we chose 2007, the most recent year before the trade collapse.

As we will see, the key measure of uncertainty for the firm is the variability of demand between the actions of the firm and the arrival of the shipment. This is the product of the time required for the shipment to arrive and the volatility of demand. Note that if the shipment arrives instantly or demand is deterministic, then we are back to deterministic models - hence deterministic models can do a better job in describing trade frequency between nearby countries than between far away trading partners.

The time needed for the inventory to arrive will be denoted by $L$. In this model, we interpret $L$ as the time difference between order and delivery. Based on anecdotical evidence, in overseas transport, $L$ typically ranges between 2-12 months as it would not only include actual shipment but administration and with just in time production, assembly as well. ${ }^{24} \lambda$ will show the (now stochastic) intensity of demand, while $\psi^{2}$, the asymptotic variance-to-mean ratio represents the relative variability of demand.

\footnotetext{
${ }^{24}$ It may include: notification of partner, discussion of details of delivery, implementation, production - depending on the good this may include assembly, order of parts, production of certain components, retooling, resetting machines - packaging, administration of delivery, delivery from factory gate to harbor, containerizing, shipping, delivery to distribution, check and verification of delivery.
} 
We will also specify an inventory policy describing the behavior of the firm. A widely used policy is the $(\mathrm{r}, \mathrm{q})$ model. This means that the firm always sends $q$ units whenever the inventory declines below the re-order point, $r$. The optimization requires firms to choose $q$ and $r$ optimally to minimize the expected logistics cost.

Though such models do not have a closed form solution in general, it can be shown, that in important respects the optimal policy is very similar to that in the deterministic case. ${ }^{25}$ In particular, the behavior of lower and upper bounds for $q^{*}, f^{*}$ and $C^{*}$ provides important clues about the shape of optimal policy. First, we have the following bounds for $q^{*}$ (Zipkin (2000)): ${ }^{26}$

$$
\sqrt{\frac{2 k}{h \omega} \lambda} \leq q^{*} \leq \sqrt{\frac{2 k \omega+b \psi^{2} L}{h \omega^{2}} \lambda}
$$

Taking logs and applying the formula $\ln (1+x) \leq x$ we get

$$
\frac{1}{2} \ln \frac{2 k}{h \omega}+\frac{1}{2} \ln \lambda \leq \ln q^{*} \leq \frac{1}{2} \ln \lambda+\frac{1}{2} \ln \frac{2 k}{h \omega}+\frac{b}{2 k \omega} \psi^{2} L
$$

We observe that the lower bound of $q^{*}$ is its value in presence of backorder costs referred to above. Hence, in presence of uncertainty, shipment size tend to be larger ceteris paribus. Another observation is that both bounds increase proportionally with $\sqrt{\lambda}$, hence it is a good approximation that $q^{*}$ increases linearly with $\sqrt{\lambda}$. Third, while the lower bound is independent of $\psi^{2} L$, the upper bound increases in it. The intuition of this result is that the larger uncertainty is, the larger shipments the firm sends in order to reduce the expected value of backorders, leading to a smaller expected number of shipments conditional on $\lambda$. The above formula shows that this effect is zero when $b=0$, and becomes stronger as the cost of backorders increases relative to inventory costs. All in all, it is possible to approximate $\ln q^{*}$ and $f^{*}$ with a relatively simple functional forms:

$$
\begin{aligned}
\ln q^{*} & \approx A_{q}+\frac{1}{2} \ln \lambda+C_{q} \psi^{2} L \\
\ln f^{*} & \approx-A_{q}+\frac{1}{2} \ln \lambda-C_{q} \psi^{2} L
\end{aligned}
$$

where $A_{q}, C_{q}$ depend on $b, h$ and $k$.

One can see that the important result of the deterministic case, that - at least in approximation - both frequency and shipment size increases linearly to the square root of demand still holds.

\footnotetext{
${ }^{25}$ See subsection 6.5.3 of Zipkin (2000).

${ }^{26} \mathrm{An}$ important difference relative to the deterministic case is that $q^{*}, f^{*}$ and $C^{*}$ are expected values. However, the reader has noticed the similarity between the lower bound here and the deterministic case comprising penalties backorder costs.
} 
The effect of uncertainty is less obvious. The main effect of increasing uncertainty is that the expected cost of backorders increases for each level of inventories. Hence, when uncertainty increases, it is optimal to increase average inventory levels in order to reduce expected backorder costs. Optimizing firms do it on two margins: they increase both their reorder points and the average shipment size. Larger shipments result in less frequent deliveries for the same demand intensity.

Uncertainty also affects total logistic costs on three channels. First, it leads to larger expected backorder costs. Second, as firms increase their inventory levels, inventory costs also increase. These two effects are somewhat mitigated by a fall in per-shipment costs. Total logistics costs can be approximated in the following way: ${ }^{27}$

$$
C^{*} \approx \tau \lambda+\left(C_{1}+C_{2} \sqrt{\psi^{2} L}\right) \sqrt{\lambda}
$$

where $C_{1}$ and $C_{2}$ are functions of $b, h$ and $k .^{28}$

This result shows that in the stochastic case the cost function remains similar to the one in the deterministic case in the sense that it is a linear function of $\lambda$ and $\sqrt{\lambda}$. The new element is that the coefficient of $\sqrt{\lambda}$ increases in demand uncertainty thanks to larger expected backorder costs and the required increase in inventory levels: total logistics cost is increasing in uncertainty, but less then proportionally. It also means that the increasing returns to logistics is also greater for more uncertain markets.

Importantly, perceived uncertainty is the product of the variance of demand $\left(\psi^{2}\right)$ and the time to ship $(L)$ : if either of them is small, than logistics cost is not effected significantly by the other one. This result is highly intuitive: the effective uncertainty the firm faces is the variability of demand between its actions and the arrival of the shipment.

This observation leads to the important consequence that firms' transportation costs can feature strong economies of scale. While this is true in the deterministic case, the stochastic case shows that uncertainty even increase this nonlinearity through its effect on the desired inventory level. The model predicts that both transportation costs and the economies of scale increase in demand uncertainty and distance.

In the simplest version of this framework, we assumed that the expected total sales $\lambda$, is given. Similarly to the deterministic case, we can now embed our model into a CES framework in order to investigate firm behavior when quantity is endogenous. The predictions of the model with respect to market size and $\tau$ are unchanged, but the nonlinearities are further magnified by uncertainty.

With endogenous sales, we can now turn to a to a key thought experiment: what

${ }^{27}$ We can approximate it with the bounds $\tau \lambda+\sqrt{\left(2 k h \omega+b^{2} \Upsilon^{2}(\omega) \psi^{2} L\right) \lambda} \leq C^{*} \leq \tau \lambda+\sqrt{2 k h \omega \lambda}+$ $b \Upsilon(\omega) \sqrt{\psi^{2} L \lambda}$ where $\Upsilon(\omega)=\frac{\phi\left(\Phi^{-1}(1-\omega)\right)}{1-\omega}$ and $\Phi, \phi$ are the cdf and the density function of the Normal distribution, respectively. The approximation in the text is valid when $\sigma$ is large enough, but based on the numerical simulations of Zipkin (2000) p. 219 the approximation works well even for relatively small $\sigma$.

${ }^{28} C_{1}=\sqrt{(2 k h \omega)}$ and $C_{2}=b \Upsilon(\omega)$. 
Figure 5: Marginal cost functions with different volatility

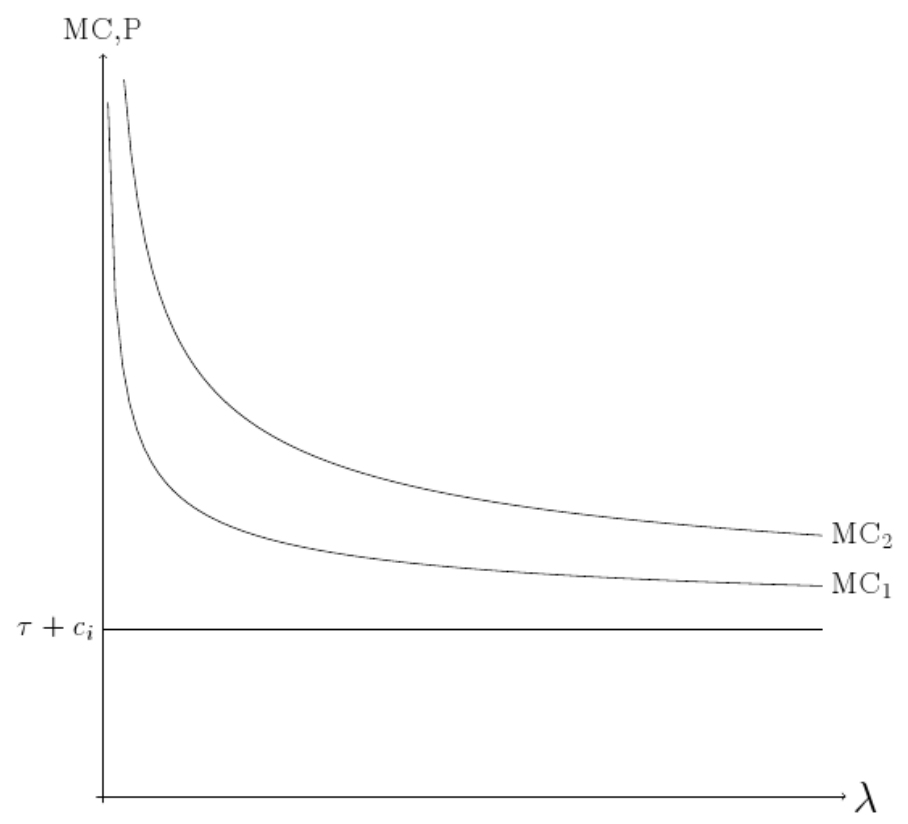

happens when uncertainty rises. To investigate this, we depicted the marginal cost functions of two similar markets with different volatility on Figure 5. As market 2 is more uncertain, prevelant marginal costs are higher for all quantity levels. Also, it is more convex, indicating that higher uncertainty leads to stronger returns to scale in the logistics technology. As a comparison, the horizontal line represents the iceberg transportation cost case, when marginal costs are constant.

Optimal behavior is shown in Figure 6 which compares two similar markets with different levels of uncertainty. Here, uncertainty reduces quantity sold, and the effect depends on the elasticity of demand and the slope of the marginal cost curve. ${ }^{29}$

When analyzing the effect of uncertainty on shipment size and the number of shipments, we should combine this observation with the previous result that - with fixed quantity - uncertainty leads to larger and less frequent shipments.

To summarize, the simple theoretical framework used here predicts that:

i) Higher uncertainty (a) reduces export value, (b) reduces the number of shipments but (c) has an ambiguous impact on the average value of shipments.

\footnotetext{
${ }^{29}$ When expressing the effect of uncertainty by implicit differentiation yields $\frac{d \lambda}{d \sqrt{\psi^{2} L}}=$ $\frac{\frac{1}{2} C_{2} \lambda}{\frac{1-\sigma}{\sigma^{2}} \frac{I^{\frac{1}{\sigma}}}{P^{\frac{1-\sigma}{\sigma}}} \lambda^{\frac{\sigma-2}{2 \sigma}}+\frac{1}{4}\left(C_{1}+C_{2} \sqrt{\psi^{2} L}\right)}<0$
} 
Figure 6: The effect of an increase in demand uncertainty

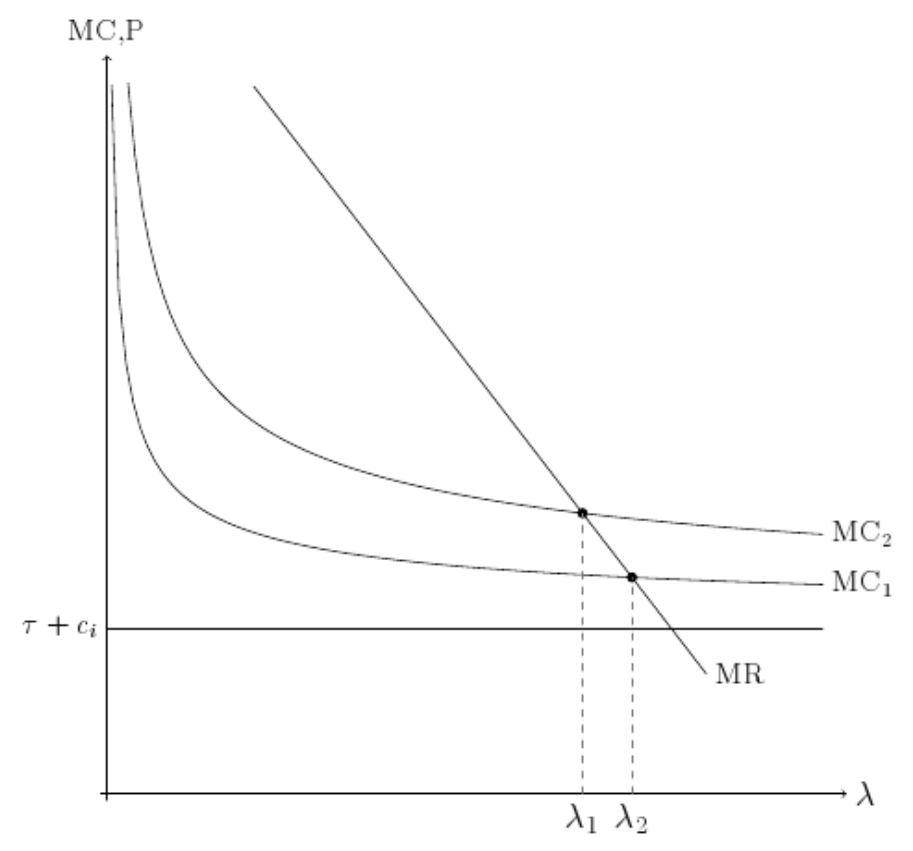

ii) Holding export value fixed, higher uncertainty reduces the number of shipment (and increases the average value per shipment).

iii) Shipment time magnifies the impact of uncertainty.

\subsection{Measuring Optimal shipment strategy under uncertainty: methodological issues}

From an empirical point of view, an important issue is the definition of uncertainty faced by exporters. Many definitions of uncertainty could be used. We consider that due to stochastic demand, firms are unaware of the final demand and hence, face uncertainty. This definition is related to business dynamics, although all aspects of a market may influence certainty of sales. To this end, we measure uncertainty by averaging volatility of firms' past (annual) sales changes for each product-destination markets prior to the year considered, back to 1999 .

We are aware that several studies considered uncertainty, stemming from productivity shocks (Bloom et al. 2012), price volatility (Hummels \& Schaur 2010) or instability of political-institutional variables (Handley \& Limao 2012). Our approach dedicated 
to the choices of individual exporters confronted to uncertainty is somewhat different, as we are concerned with the volatility of demand itself, and its use will complement existing approaches.

Our uncertainty variable $U_{n c e r t} t_{j k}$ is a proxy for the variance of the distribution of demand from our model. It captures the yearly average uncertainty of sales faced by $N$ French firms (indexed by $i$ ) over the period 1999-2006 on a specific market $(j, k)$ when deciding to ship, i.e. the variance of sales variations over time on the market.

More specifically, uncertainty is measured in two steps at the product $j$ and destination $k$ level. First we define annual growth rates (differences in log sales) of a given firm and calculate the standard deviation of these rates. Second, we take the average of these values over firms at a given $(j, k)$ market. High volatility reflects a higher uncertainty of the demand addressed to firms and may be related to both variations in overall annual demand on the market and/or the process of reallocation of market shares across firms.

$$
\text { Uncert }_{j k}=(1 / N) \sum_{i=1}^{N} \sqrt{\left[1 /(n-1) \sum_{t=1}^{n} \dot{X}_{i j k, t}^{2}-\left(1 /(n-1) \sum_{t=1}^{n} \dot{X}_{i j k, t}\right)^{2}\right]}
$$

where $\dot{X}_{i j k, t}$ is the log change in the value of exports of product $j$ by firm $i$ to destination $k$ over the one-year period $(t-1)$ to $t .{ }^{30}$ In all regression analysis, we take $\log$ of Uncert ${ }_{j k}$.

Robustness estimations with alternative measures of uncertainty are provided in the next section.

As in section 3, we relate uncertainty Uncert $_{i j k}$ to (1) total (annual) shipment value

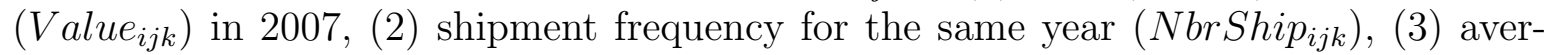
age shipment value $\left(A v g V a l_{i j k}\right)$. All dependent variables (value, number of shipments and average value) are presented in logs and we estimate the model at firm-productdestination $(i, j, k)$ level. This yields:

$$
\ln Z_{i j k}=\alpha+\beta_{1} \text { Uncert }_{j k}+\eta_{k}+\theta_{i j}+\epsilon_{i j k}
$$

with $Z_{i j k}=\left(\right.$ Value $\left._{i j k}, N b r S h i p_{i j k}, A v g V a l_{i j k}\right)$ and $\theta_{i j}$ fixed effects that control for unobserved firm/product characteristics. ${ }^{31}$

\footnotetext{
${ }^{30}$ We use information on changes in firm sales observed at least three times on the same (destination/product) market over 1999-2006.

${ }^{31}$ Another selection issue arises from the fact that we do not observe all firms/products on all markets and that this selection is not random. The potential negative correlation arising from selection into export markets would however bias our results towards zero. As robustness, we follow Crozet et al. (2012) and estimate Equation 17 for Value $_{i j k}$ considering explicitly censoring points depending on markets using the minimum positive value of exports observed on each market. This methodology
} 
We introduce destination specific fixed effects that shall pick up costs associated with destination market interest rates, as well as doing business types of costs of each shipment $^{32}$. As the identification is on the cross section, these fixed effects shall control for most variables of the model apart from the product-destination specific uncertainty, the effect of which we look for. ${ }^{33}$

\subsection{How export margins adjust to uncertainty}

Table 4 presents results for our baseline regressions. The three first columns do not control for total sales: the dependent variable for the first column is the log of annual sales, followed by columns on log number of shipments (months) and then, log average value. In column (4) and (5) of Table 4 we control for total sales and the dependent variable is the number of shipments and the log average value respectively. Let us interpret results in light of our predictions.

Table 4: Stochastic model - core results

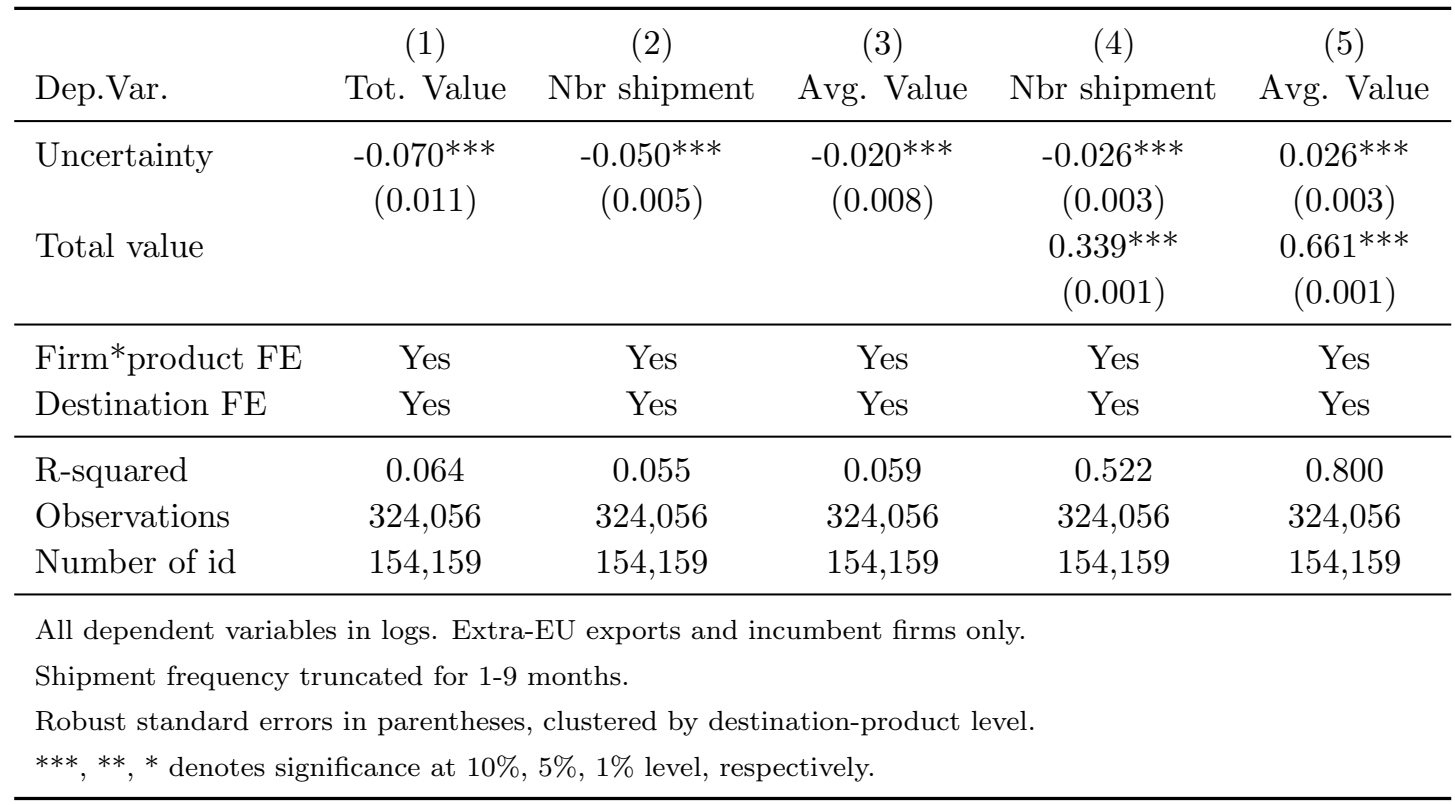

is however not directly applicable to the breakdown in the shipment and average value margins. As expected, this methodology yields a larger coefficient on uncertainty. Results are available on request.

${ }^{32}$ According to Cameron \& Miller (2011), it is more conservative to use two-way clustering at the destination and the product level or the destination and firm level. We tested models accordingly, and it did not change results qualitatively. Results are available on request.

${ }^{33}$ One can expect that products with high depreciation rate (perishables) react differently. Unfortunately food items, which is a clear candidate, is also seasonal and as France ships little raw food overseas, is not a convincing candidate. Fast fashion is hardly distinguishable at 6-digit level. Instead we tried intermediate goods (by BEC category) as shipping these goods are rather time sensitive. There was no apparent difference. Results are available on request. 


\section{Uncertainty reduces export value and number of shipments}

Empirically, higher uncertainty will reduce shipment value as well as shipment frequency and value per shipment. According to our baseline results, a firm facing a 10\% higher uncertainty for a given product at a given market is selling $0.7 \%$ less at that market. This can be decomposed into a 0.5 percent fall in the number of shipments and $0.2 \%$ decrease in shipment size. In line with our predictions, the fall in shipment size is larger, because it is optimal to send relatively larger shipments in order to uphold a larger inventory level. Finally, as expected, higher uncertainty has an ambiguous impact on the average value of shipments. However, since we do not control for total sales, no conclusion can be derived from the estimated parameter: we simply observe that the negative impact of reduced total sales overcompensates the positive impact of less frequent and larger shipments to uncertain markets.

\section{Holding export value fixed, uncertainty reduces shipment frequency and increases the average value per shipment.}

So far we have considered the unconstrained model. The number of shipments will also fall because even for the same amount of sales, firms will choose to send fewer shipments when uncertainty is high (exactly the opposite for package size). We run the same regression as before, controlling for the total value exported by the firm to the given market, and our estimated equation becomes:

$$
\ln Z_{i j k}=\alpha+\beta_{1} \text { Uncert }_{j k}+\beta_{2} \ln \text { Value }_{i j k}+\eta_{k}+\theta_{i j}+\epsilon_{i j k}
$$

with $Z_{i j k}=\left(\right.$ NbrShip ijk,$\left.A v g V a l_{i j k}\right)$.

Results presented in columns (4) and (5) of Table 4 confirm that controlling for the annual total sales, the product-destination market with higher uncertainty is associated with fewer but larger transactions. For given value exported, a $10 \%$ higher uncertainty is associated with $0.26 \%$ less transactions of $0.26 \%$ larger value each. Note that when we control for the total export of the firm on the (product/destination) market, the coefficient on uncertainty is by definition opposite for the number and the average size of shipment. Of course, total sales is fully endogenous as a control for number of shipments an issue we'll revisit at the robustness section.

\section{Shipment time magnifies the impact of uncertainty.}

Our last prediction is that travel time magnifies the impact of uncertainty on exporters' decisions. We use distance to France as a proxy for travel time. The number of days necessary to reach the destination market by ship is indeed directly related to the physical distance. This proxy for travel time does however not work well for air freight. We therefore restrict our sample to maritime shipments which represent $52 \%$ of our 
sample. ${ }^{34}$ To test this, we interact in Table 5 our distance and uncertainty variables and add a cross term of uncertainty and distance. Equation 17 becomes:

$$
\ln \operatorname{NbrShip}_{i j k}=\alpha+\beta_{1} \text { Uncert }_{j k}+\beta_{2} \ln \operatorname{Dist}_{k} * \text { Uncert }_{j k}+\eta_{k}+\theta_{i j}+\epsilon_{i j k} .
$$

We estimate two versions of this model. First, we consider distance linearly in the interaction, followed by a model introducing a dummy for far away transactions. Regarding the linear model, note that the positive coefficient on uncertainty alone is compensated by the negative interaction term since the average value of $\log _{\text {Dist }}$ is 8.31 and its minimum value is 6.08 . Using a non parametric specification, we confirm that for all markets, the combined effect is negative for maritime routes, and stronger for markets beyond $6,000 \mathrm{~km}$ (column 4). Note that countries closer than $6,000 \mathrm{~km}$ include Middle Eastern countries, African countries up to Congo, Asian countries up to Uzbekistan. Thus, distant countries in the Americas, South part of Africa, China, India and East Asia, Oceania are areas where uncertainty matters most.

Columns (1) and (3) present basic results, Columns (2) and (4) include the control of total values as well. In all cases, we find evidence of the magnification effect of travel time.

\footnotetext{
${ }^{34}$ Data on the mode of transport at the frontier are from Comext, which details the mode of transport of extra-EU trade by destination and HS6 digit level and differentiate between sea, rail, road, air, postal consignment, fixed transport installations, inland water transports or own propulsion. We use the information on the main mode of transport by market (product $\times$ destination) to identify shipments by sea from other modes of transport.
} 
Table 5: The role of travel time (distance)

\begin{tabular}{|c|c|c|c|c|}
\hline Dep. Var & $\begin{array}{c}(1) \\
\text { Nbr ship. }\end{array}$ & $\begin{array}{c}(2) \\
\text { Nbr ship. }\end{array}$ & $\begin{array}{c}(3) \\
\text { Nbr ship. }\end{array}$ & $\begin{array}{c}(4) \\
\text { Nbr ship. }\end{array}$ \\
\hline Uncertainty & $\begin{array}{l}0.116^{*} \\
(0.070)\end{array}$ & $\begin{array}{c}0.169^{* * *} \\
(0.048)\end{array}$ & $\begin{array}{c}-0.044^{* * *} \\
(0.008)\end{array}$ & $\begin{array}{c}-0.012^{* *} \\
(0.005)\end{array}$ \\
\hline Distance*Uncertainty & $\begin{array}{c}-0.020^{* *} \\
(0.008)\end{array}$ & $\begin{array}{c}-0.023^{* * *} \\
(0.006)\end{array}$ & & \\
\hline $6,000 \mathrm{~km} *$ Uncertainty & & & $\begin{array}{c}-0.021^{* *} \\
(0.011)\end{array}$ & $\begin{array}{c}-0.026^{* * *} \\
(0.008)\end{array}$ \\
\hline Total value & & $\begin{array}{c}0.344^{* * * *} \\
(0.001)\end{array}$ & & $\begin{array}{c}0.344^{* * *} \\
(0.001)\end{array}$ \\
\hline Firm*product FE & Yes & Yes & Yes & Yes \\
\hline Destination FE & Yes & Yes & Yes & Yes \\
\hline R-squared & 0.051 & 0.521 & 0.051 & 0.521 \\
\hline Observations & 174,111 & 174,111 & 174,111 & 174,111 \\
\hline Number of id & 82,551 & 82,551 & 82,551 & 82,551 \\
\hline \multicolumn{5}{|c|}{$\begin{array}{l}\text { All dependent variables in logs. Extra-EU exports and incumbent firms only. } \\
\text { Shipment frequency truncated for } 1-9 \text { months. Maritime shipment only. } \\
\text { Robust standard errors in parentheses, clustered by destination-product level. } \\
* * *, * *, * \text { denotes significance at } 10 \%, 5 \%, 1 \% \text { level, respectively. }\end{array}$} \\
\hline
\end{tabular}

\subsection{Robustness}

We analyze here the robustness of our findings using alternative measures of uncertainty, estimation methods and sample restrictions.

Regarding alternative measures to our uncertainty variable, our benchmark measure looked at firm sales volatility in a given $(j, k)$ market. We now consider uncertainty based on variation of demand over time at the aggregate level (total imports of a country in a product over a quarter). We accordingly drop the firm dimension of sales based on the argument that firms may look at demand uncertainty from the vantage point of overall demand fluctuations based on past experience. To capture this, we created the "Aggregate uncertainty" variable as the relative standard deviation of quarterly sales $(j, k)$ for 32 quarters (1999-2006). We added zeros to quarters when annual sales that year were non zero and applied a simple seasonal adjustment by calculating quarter dummies as deviations from a trend.

Both our benchmark and the aggregate uncertainty variables may be endogenous to the $(i, j, k)$ shipment. To avoid this, our second alternative variable "Aggregate uncertainty ITA" replaces relative standard deviation overtime of French Firms, calculated by those experienced by Italian firms. Of course, this means a great deal of loss of observations, as we can only observe markets served by both French and Italian firms.

Our third alternative measure is a firm's experience in a given market. As local 
experience helps a firm to know its market better, it can reduce uncertainty. A firm's experience in a given market $(j, k)$ is simply the number of years since entry on the export market (1994 being the first available year). Of course this variable captures firm age and overall export experience. However, given our firm-product fixed effect specification, this shall be partially out. Note that this variable has the opposite expected sign as all other, as a greater number represents more certainty while for other variables, it implies greater uncertainty.

The last alternative measure of uncertainty uses the firm level and time dimension of our data but the cross-sectional variation of growth rate across firms in a given market, in the spirit of Bloom et al. (2012). "Uncertainty cross" is the variance of firms' yearly growth rates on a given destination and product markets, using information on firms exporting over the 1999-2006 period.

Results are presented in Table 6 for the number of shipments, comparing the effect to the benchmark case, one by one ${ }^{35}$. Results presented before are confirmed as all uncertainty variables behave the similar way as our benchmark.

Table 6: Alternative uncertainty measures

\begin{tabular}{|c|c|c|c|c|c|}
\hline & $(1)$ & $(2)$ & $(3)$ & $(4)$ & $(5)$ \\
\hline & \multicolumn{5}{|c|}{ log nbr shipments } \\
\hline Uncertainty & $\begin{array}{c}-0.050^{* * *} \\
(0.006)\end{array}$ & & & & \\
\hline Agg. uncert & & $\begin{array}{c}-0.165^{* * *} \\
(0.006)\end{array}$ & & & \\
\hline Agg. uncert ITA & & & $\begin{array}{c}-0.020^{* * *} \\
(0.003)\end{array}$ & & \\
\hline Experience by dest*prod & & & & $\begin{array}{c}0.033^{* * *} \\
(0.001)\end{array}$ & \\
\hline Uncertainty cross & & & & & $\begin{array}{c}-0.066^{* * *} \\
(0.008)\end{array}$ \\
\hline Firm*product FE & Yes & Yes & Yes & Yes & Yes \\
\hline Destination FE & Yes & Yes & Yes & Yes & Yes \\
\hline R-squared & 0.054 & 0.064 & 0.054 & 0.067 & 0.054 \\
\hline Observations & 290,281 & 290,281 & 290,281 & 290,281 & 290,281 \\
\hline Number of id & 143,737 & 143,737 & 143,737 & 143,737 & 143,737 \\
\hline $\begin{array}{l}\text { All dependent variables in } \\
\text { Shipment frequency trun } \\
\text { Robust standard errors in } \\
* * *,{ }^{* *}, * \text { denotes signific }\end{array}$ & $\begin{array}{l}\text { logs. Extra } \\
\text { ted for } 1-9 \\
\text { parentheses } \\
\text { nce at } 10 \%\end{array}$ & $\begin{array}{l}\text { EU exports } \\
\text { months. } \\
\text { clustered by } \\
5 \%, 1 \% \text { leve }\end{array}$ & $\begin{array}{l}\text { and incumb } \\
\text { destinatio } \\
\text {, respectiv }\end{array}$ & $\begin{array}{l}\text { ent firms o } \\
\text {-product l } \\
\text { ly. }\end{array}$ & $\begin{array}{l}\text { ly. } \\
\text { vel. }\end{array}$ \\
\hline
\end{tabular}

\footnotetext{
${ }^{35}$ Incidentally the benchmark case is giving identical results from above, e.g. -0.050 for the original uncertainty variable in Panel A with 290,281 observations compared to 324,056 observations. The standard error of the estimated parameter is indeed different
} 
Alternative estimation methods and full sample were also considered in additional robustness tests. Results are presented in Table 7 . We show here the results of our preferred specification for alternative estimators and systematically compare with estimations done with the full sample (instead of keeping only the 1-9 shipments).

Column (1) reproduces column (3) from Table 4 to ease comparability. Column (2) shows baseline results for whole sample, ie. including observations with shipments 1012. Notice that the number of observations is not so different. However, the estimated coefficient is higher $(-0.050$ vs -0.088$)$, and this remains true for other specifications.

This is followed by two random effect effect models - one simple way to treat potential over-specification (Matyas et al. 2012). Results confirm earlier results while showing a coefficient estimate somewhat larger than before. We carried out truncation in this case as well, with no apparent change. In column (5) we present results with a Tobit model, in which all observations with more than 9 months are treated as censored ${ }^{36}$. Once again, the key negative relationship between shipment frequency and uncertainty is confirmed.

Looking at results at Table 7 we can see that point estimates of the uncertainty variable vary between -0.050 (our baseline estimate) and -0.161 suggesting that presenting results on the truncated sample with destination fixed effects is a rather conservative approach.

Table 7: Different estimators, incumbents only

\begin{tabular}{|c|c|c|c|c|c|}
\hline & (1) & (2) & (3) & (4) & (5) \\
\hline & \multicolumn{5}{|c|}{ log nbr shipments } \\
\hline & \multicolumn{2}{|c|}{ OLS Fixed Effects } & \multicolumn{2}{|c|}{ OLS Random effects } & Tobit RE \\
\hline Sample & baseline & All transactions & baseline & All transactions & All transactions \\
\hline Uncertainty & $\begin{array}{c}-0.050^{* * *} \\
(0.005)\end{array}$ & $\begin{array}{c}-0.088^{* * *} \\
(0.006)\end{array}$ & $\begin{array}{c}-0.134^{* * *} \\
(0.007)\end{array}$ & $\begin{array}{c}-0.161^{* * *} \\
(0.008)\end{array}$ & $\begin{array}{c}-0.137^{* * *} \\
(0.004)\end{array}$ \\
\hline Firm* product FE & Yes & Yes & - & - & - \\
\hline Destination FE & Yes & Yes & Yes & Yes & Yes \\
\hline R-squared & 0.055 & 0.099 & & & \\
\hline Observations & 324,056 & 350,849 & 324,056 & 350,849 & 350,849 \\
\hline Number of id & 154,159 & 157,944 & 154,159 & 157,944 & 157,944 \\
\hline $\begin{array}{l}\text { All dependent var } \\
\text { Robust standard } \\
* * *, * *, * \text { denotes }\end{array}$ & $\begin{array}{l}\text { bles in logs } \\
\text { ors in pare } \\
\text { gnificance }\end{array}$ & $\begin{array}{l}\text { Extra-EU export } \\
\text { ntheses, clustered } \\
\text { at } 10 \%, 5 \%, 1 \% \text { le }\end{array}$ & $\begin{array}{l}\text { and incum } \\
\text { y destinati } \\
\text { el, respecti }\end{array}$ & $\begin{array}{l}\text { ent firms only. } \\
\text {-product level. } \\
\text { ly. }\end{array}$ & \\
\hline
\end{tabular}

Finally, to reflect the potential inconsistency resulting from heteroscedasticity in data, we use Poisson pseudo maximum likelihood estimator proposed by Santos Silva \& Tenreyro (2006). This methodology is consistent with average value of shipment

\footnotetext{
${ }^{36}$ Changing the censoring limit to 8 or 10 months does not change the results importantly.
} 
estimation and the number of shipments proxied by the number of non-zero monthly exports, at the firm-destination-product level. Poisson PML results with destination fixed effects - presented in Table 9 of the Appendix - confirm key results using the sample limited to incumbent firms.

Finally, as noted earlier, we made several decisions regarding the use of sample and estimation model. All these decisions were based on creating a sample that best fits our model and offer conservative estimates. However, it is important to see if changing any of key calls would alter results in a meaningful fashion. To test robustness of our core result, beyond alternatives offered here, we repeated our core regressions regressions for alternative samples:

1. including EU countries

2. including all firms rather than just incumbents

3. employing no censoring and thus having all shipments (up to 12)

4. excluding air and road travel, i.e. focusing on cases when we can be certain of including maritime shipment only

Results presented in Table 8 in the Appendix confirm our findings. Additional to all these four alterative samples, we also control for total imports (excluding France) of the given product at that year. Columns 5,10,15 and 20 report results confirming earlier estimates.

Overall, we can argue that our core result of higher uncertainty reducing shipment frequency is robust to alternative estimation methods such as Tobit or PPML as well as to variations in sample characteristics. 


\section{Conclusion}

Understanding the role of shipment frequency and showing that it is a new margin helps us understanding the role of increasing returns in shipping cost: larger markets are served more frequently but also with larger batches. More interestingly, firms may use this margin to adjust to different business conditions at various (productdestination) markets. When there is high uncertainty creating high potential costs, firms may mitigate these costs by flexibly adjusting their shipment frequency. Micro adjustments by firms on the number of shipments may therefore dampen the impact of uncertainty on aggregate trade flows. As long as trade liberalization, technological development or better infrastructure reduces the time required to ship, it leads to lower logistics costs and more trade.

A simple inventory management model reproduces the stylized facts present in the French data in a deterministic setting as well as in presence of uncertainty. Uncertainty of demand a firm faces in a given market is linked to her decision on how to serve that demand. Firms react by adjusting their shipment value as well as their shipment frequency. The number of shipments - measured as the number of months with nonzero exports - is an additional extensive margin allowing additional flexibility to firms in serving distant markets. Our empirical analysis confirms that firms respond to demand uncertainty by reducing the number of their shipments and increasing the average value per shipment for a given value exported in a year. We also show that the impact of uncertainty is magnified by the time needed to serve the destination market from the production location.

Finally, we predict and observe that decreasing time to ship increases more the number of shipments and total exports to more distant and more uncertain markets. In other words, progress made in terms of reducing shipping costs and time (e.g. containerization) has been relatively more conducive to more frequent and larger shipments to relatively more distant or more uncertain markets. This conclusion applies to rapidly growing but remote markets, e.g. China for European exporters. Increased demand has led to more frequent and more voluminous shipments while reduction in shipping times

has smoothed the negative impact of uncertainty leading firms to ship less voluminous batches more frequently. 


\section{Appendix}

Figure 7: Frequency of shipments, number of months, 2007, all and extra-EU
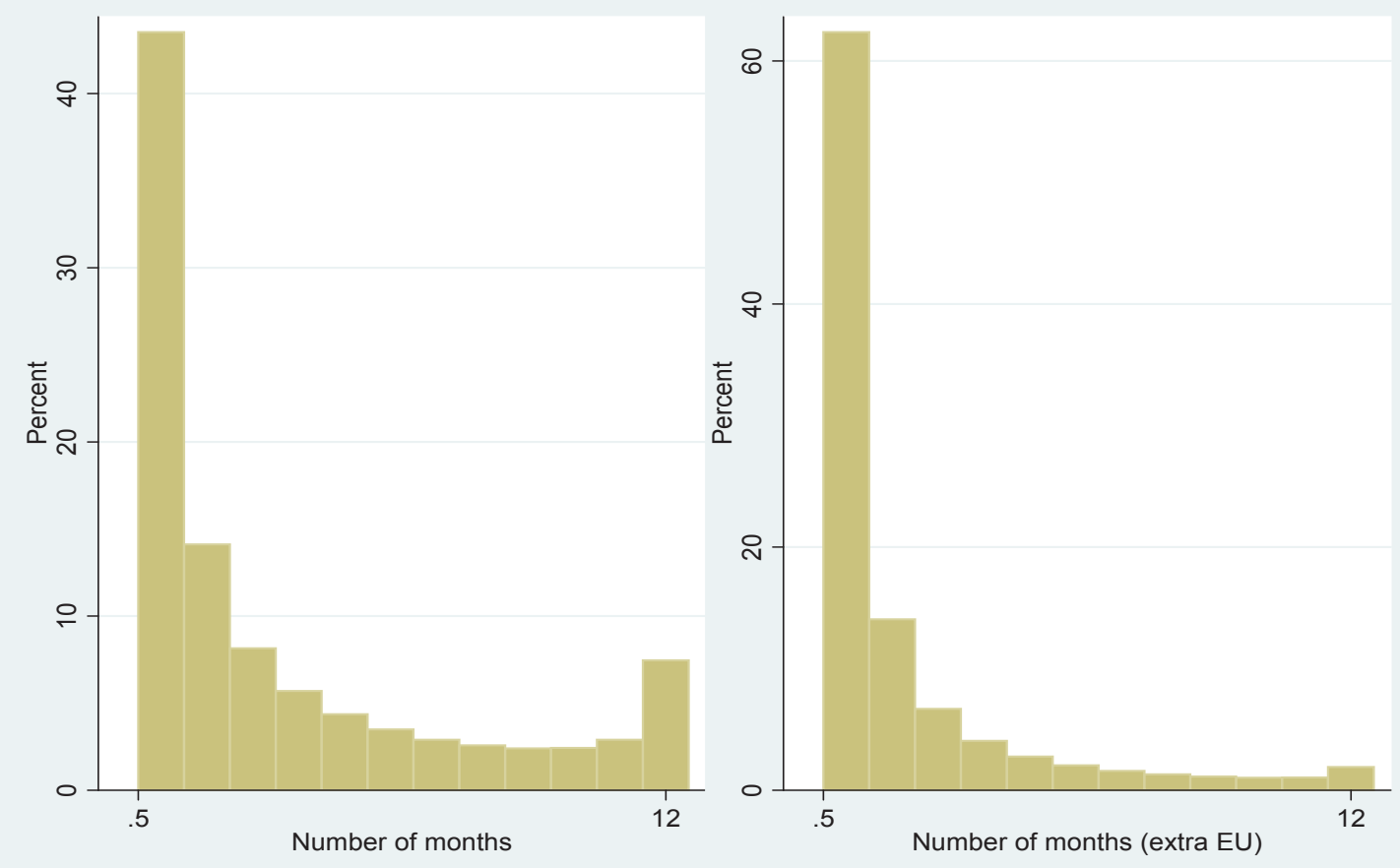

Notes: firm-destination-product (HS6) level. Source: French Customs, authors' calculation. 


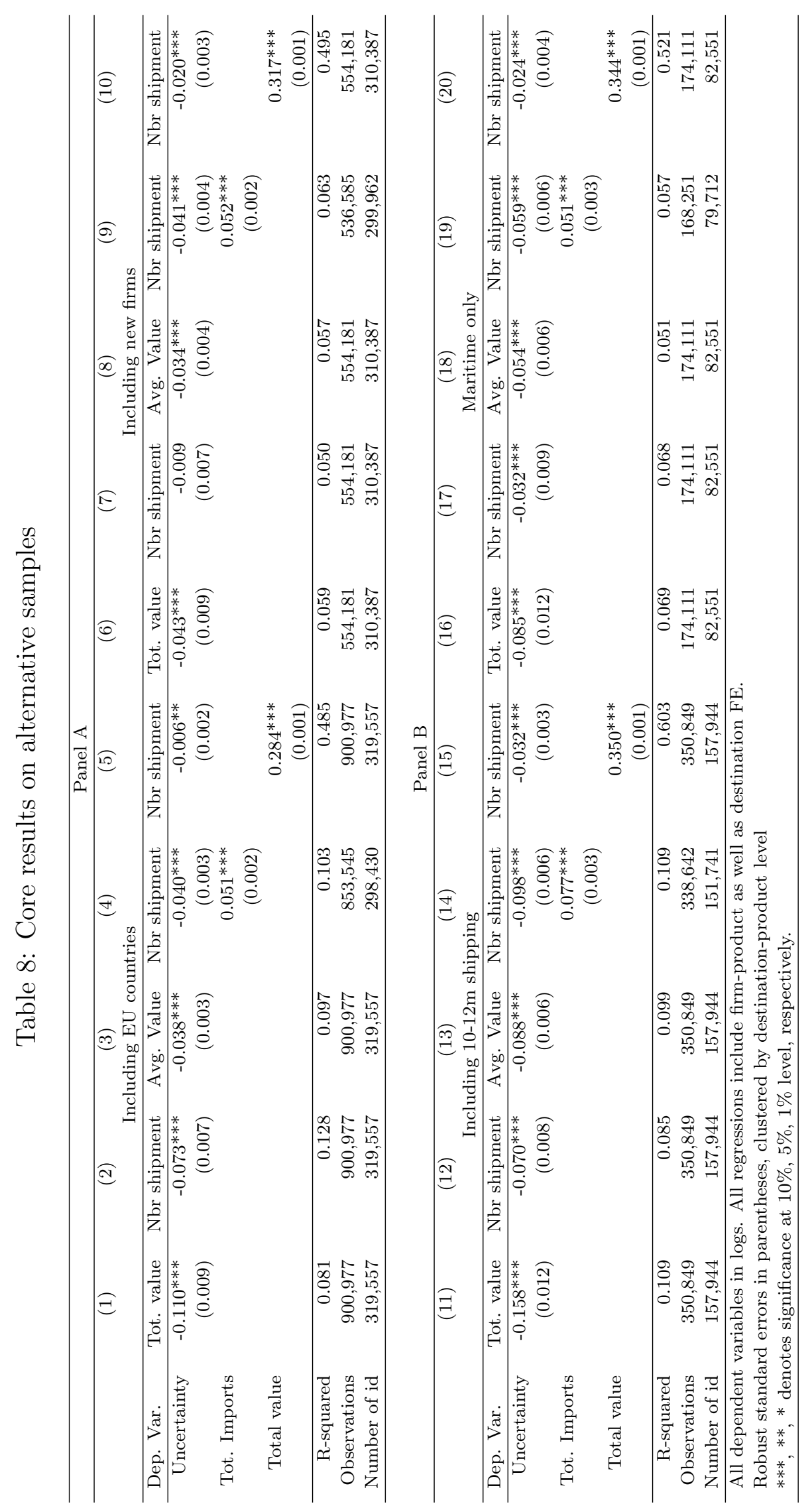


Table 9: Poisson model

\begin{tabular}{|c|c|c|c|c|}
\hline & (1) & (2) & (3) & (4) \\
\hline & \multicolumn{4}{|c|}{ Poisson } \\
\hline Dep. Var. & Tot. value & Nbr shipment & Avg. Value & Nbr shipment \\
\hline Uncertainty & $\begin{array}{c}-0.007^{* * *} \\
(0.001)\end{array}$ & $\begin{array}{c}-0.062^{* * *} \\
(0.006)\end{array}$ & $\begin{array}{c}-0.002^{* *} \\
(0.001)\end{array}$ & $\begin{array}{c}-0.023^{* * *} \\
(0.005)\end{array}$ \\
\hline Total value & & & & $\begin{array}{c}0.444^{* * *} \\
(0.002)\end{array}$ \\
\hline Firm*Product FE & Yes & Yes & Yes & Yes \\
\hline Destination FE & Yes & Yes & Yes & Yes \\
\hline Observations & 214,889 & 197,070 & 214,889 & 197,070 \\
\hline Number of id & 44,992 & 37,363 & 44,992 & 37,363 \\
\hline Log Lik & -338823 & -147336 & -325840 & -124776 \\
\hline $\begin{array}{l}\text { All dependent variabl } \\
\text { clustered by destinati } \\
* * *, * *, * \text { denotes sig }\end{array}$ & $\begin{array}{l}\text { in logs. Robu } \\
\text { level (1-3), de } \\
\text { cance at 10\% }\end{array}$ & $\begin{array}{l}\text { standard errors } \\
\text { tination-product } \\
5 \%, 1 \% \text { level, res }\end{array}$ & $\begin{array}{l}\text { parentheses, } \\
\text { vel (4). } \\
\text { ctively. }\end{array}$ & \\
\hline
\end{tabular}




\section{$7 \quad$ References}

\section{References}

Albornoz, F., Calvo Pardo, H. F., Corcos, G. \& Ornelas, E. (2012), 'Sequential exporting', Journal of International Economics 88, 17-31.

Alessandria, G., Kaboski, J. P. \& Midrigan, V. (2010), 'Inventories, lumpy trade, and large devaluations', The American Economic Review 100(5), pp. 2304-2339.

Alessandria, G., Kaboski, J. P. \& Midrigan, V. (2011), 'Us trade and inventory dynamics', American Economic Review 101(3), 303-307.

Araujo, L. \& Ornelas, E. (2007), Trust-based trade, Technical report, CEP Discussion Papers dp0820, Centre for Economic Performance, LSE.

Ariu, A. (2011), The margins of trade: Services vs goods, mimeo, University of Leuven.

Arkolakis, C. (2010), 'Market penetration costs and the new consumers margin in international trade', American Economic Review 118(6), 1151-1199.

Baumol, W. J. (1952), 'The transactions demand for cash: An inventory theoretic approach', Quarterly Journal of Economics 66(4), 545-556.

Behrens, K., Corcos, G. \& Giordano, M. (2013), 'Trade crisis? what trade crisis?', Review of Economics and Statistics 95(2), 702-709.

Behrens, K. \& Picard, P. M. (2011), 'Transportation, freight rates, and economic geography', Journal of International Economics 85(2), 280-291.

Berthou, A. \& Vicard, V. (2013), Firms' Export Dynamics: Experience versus Size, Working paper 445, Banque de France.

Bloom, N. (2009), 'The impact of uncertainty shocks', Econometrica 77(3), 623-685.

Bloom, N., Floetotto, M., Jaimovich, N., Saporta-Eksten, I. \& Terry, S. J. (2012), Really uncertain business cycles, NBER Working Papers 18245, National Bureau of Economic Research, Inc.

Bloom, N. \& Van Reenen, J. (2007), 'Measuring and explaining management practices across firms and countries', Quarterly Journal of Economics 122(4), 1351-1408.

Cameron, A. C. \& Miller, D. L. (2011), Robust Inference with Clustered Data", CRC Press, chapter Handbook of Empirical Economics and Finance, pp. 1-28.

Crozet, M., Head, K. \& Mayer, T. (2012), 'Quality sorting and trade: Firm-level evidence for french wine', Review of Economic Studies 79(2), 609-644. 
Dixit, A. K. \& Pindyck, R. S. (1994), Investment under Uncertainty.

Eaton, J., Eslava, M., Kugler, M. \& Tybout, J. (2008), Export dynamics in colombia: Firm-level evidence, Borradores de Economia 522, Banco de la Republica de Colombia.

Eaton, J., Kortum, S., Neiman, B. \& Romalis, J. (2011), Trade and the global recession, Working Papers 16666, NBER.

Evans, C. L. \& Harrigan, J. (2005), 'Distance, time, and specialization: Lean retailing in general equilibrium', American Economic Review 95(1), 292-313.

Handley, K. \& Limao, N. (2012), Trade and investment under policy uncertainty: Theory and firm evidence, NBER Working Papers 17790, National Bureau of Economic Research, Inc.

Harrigan, J. (2010), 'Airplanes and comparative advantage', Journal of International Economics 82(2), 181-194.

Hornok, C. \& Koren, M. (2011), Administrative barriers and the lumpiness of trade, Working Papers 14, CEFIG.

Hummels, D. L. \& Schaur, G. (2010), 'Hedging price volatility using fast transport', Journal of International Economics 82(1), 15-25.

Hummels, D. \& Schaur, G. (2013), Time as a trade barrier, NBER Working Papers 17758, forthcoming American Economic Review, 2013, National Bureau of Economic Research, Inc.

Iacovone, L. \& Javorcik, B. S. (2010), 'Multi-product exporters: Product churning, uncertainty and export discoveries*', The Economic Journal 120(544), 481-499.

Kleinert, J. \& Spies, J. (2011), Endogenous transport costs in international trade, IAW Discussion Papers 74, Institut für Angewandte Wirtschaftsforschung.

Kropf, A. \& Saure, P. U. (2012), Fixed costs per shipment, Working Papers 2012-13, Swiss National Bank.

Matyas, L., Hornok, C. \& Pus, D. (2012), The formulation and estimation of random effects panel data models of trade, MPRA Paper 36789, University Library of Munich, Germany.

Mayer, T. \& Ottaviano, G. (2011), Market size, competition, and the product mix of exporters, Working Papers 16959, NBER.

Novy, D. \& Taylor, A. (2013), Trade and uncertainty, Working Papers mimeo. 
Santos Silva, J. M. C. \& Tenreyro, S. (2006), 'The log of gravity', The Review of Economics and Statistics 88(4), 641-658.

Tobin, J. (1956), 'The interest elasticity of the transactions demand for cash', The Review of Economics and Statistics 38(3), 241-247.

Zipkin (2000), Foundations of Inventory Management. 